\title{
CHARACTERISTICS OF SILICONE COMPOSITES FOR HIGH VOLTAGE INSULATIONS
}

\author{
Hidayatullah Khan', Muhammad Amin² and Ayaz Ahmad'1 \\ ${ }^{1}$ Electrical Engineering Department, COMSATS Institute of Information Technology, Wah Cantt, 47040, Pakistan \\ ${ }^{2}$ Electrical Engineering Department, Ghulam Ishaq Khan Institute of Engineering Sciences and Technology, \\ Topi, 23460, Pakistan
}

Received: January 01, 2018

\begin{abstract}
Silicone rubber ( $\mathrm{SiR})$ composites have been widely used for high voltage (HV) electrical and non-electrical applications for the last three decades. To increase the long-term performance of SiR composites under diverse environmental, mechanical and electrical stresses; detailed characterization and aging analysis is required. This review article presents a comprehensive survey on SiR composites that are used in HV applications. Particular emphasis is on silicon (Si) applications, chemistry, polymerization, silicone rubber properties enhancement by addition of fillers, composite materials, engineering requirements of polymer insulants, overview of high voltage (HV) electrical insulators and their aging.

In addition, this review article includes appropriate discussions concerning the influence of fillers (micro/nano-sized) on the physical, thermal, mechanical and electrical properties of base polymer. Tensile strength, elongation at break, hardness, thermal degradation, dielectric strength, surface resistivity, volume resistivity, tracking/erosion resistance, partial discharge and water immersion resistance of $\mathrm{SiR}$ composites are analyzed.

Finally, it was inferred that in order to diversify the SiR blends with micro/nano fillers and optimize their properties for particular applications further research work must be conducted.
\end{abstract}

\section{INTRODUCTION}

In electrical distribution/transmission lines and substations, the electrical insulator is a very important component. Porcelain/ceramic and glass insulators exhibit satisfactory mechanical, surface and ultraviolet-resistance properties. However, surface wettability, brittleness and heavy weight are the primary drawbacks of glass and ceramic insulants for high voltage (HV) dielectric applications [1,2]. Since 1970s, the silicone rubber ( $\mathrm{SiR}$ ) and ethylene-propylene-diene-monomer rubber (EPDM) are two basic polymeric insulants, which have been widely used for HV applications [3]. Owing to their light weight, excellent insulation, easy installation/transportation, better mechanical, thermal and electrical properties, the polymeric insulators are gradually replacing conventional glass and ceramic insulators for HV transmission and distribution systems [4].

In a variety of electrical applications (insulators, bushing coatings) SiR dielectrics are extensively applied, which are characterized by stable thermal performance, excellent corona resistance, aging, and ozone. In addition, hydrophobicity and their recovery from temporary-loss is the most significant feature of $\mathrm{SiR}$ materials. However, in $\mathrm{HV}$ insulation applications, these insulants (due to organic nature) are affected by electrical (corona, partial discharge, dry-band arcing) and non-electrical (chemical, moisture, temperature, UV, cyclic load) stresses, which lead to physical tracking/erosion and insulation breakdown $[2,5,6]$. Therefore, over age, the material degradation caused by UV, acidic rain, heat,

Corresponding author: H. Khan, e-mail: hidayat.msk@gmail.com 
mechanical and electrical stresses will influence the insulator performance (electrical, mechanical and thermal performances) $[7,8]$. These long-term deteriorations in insulator characteristics under the influence of various stresses are known as aging [9].

Even now, the tracking/erosion, water/moisture penetration, and aging are major dilemmas of $\mathrm{HV}$ polymer insulators, which are yet to be investigated [10]. To improve the performance and reliability of polymeric insulators, various phenomenon like aging, tracking and erosion have been investigated by incorporating micro/nano-sized inorganic particles into polymer matrix worldwide $[11,12]$.

RICHARD'S 1960, prognostication about the future of nanotechnology is especially suitable for present investigations of $\mathrm{HV}$ polymer insulants [13]. In-order to formulate polymer composites for HV insulations, many scholars have studied, the amalgamation effect of micro/nano-sized particles (fillers) into solid insulating materials. Particles such as micro/nano-sized silica $\left(\mathrm{SiO}_{2}\right)$ and alumina-trihydrate $\left(\mathrm{Al}_{2} \mathrm{O}_{3} \cdot 3 \mathrm{H}_{2} \mathrm{O}(\mathrm{ATH})\right)$ have gained attention owing to their enhanced thermal, mechanical, fire retardant, volume/surface resistivity, tracking/erosion, water/moisture penetration, and weathering properties of base polymer [14-18].

Amin et al. [19-28], studied the influence of multiple stresses (electrical and non-electrical) on aging behavior of polymeric insulators for HV applications through lab as well as field aging (simulating Pakistan environment). Salman et al. [20,21,2426,29 ], focused on natural aging of silicone rubber and thermoplastic elastomer (TPE) insulators in clean and polluted (industrial) environment. Likewise, Ali et al.[30, 31], examined the influence of micro$\mathrm{SiO}_{2}$ (of size: $5 \mu \mathrm{m}$ ) and nano- $\mathrm{SiO}_{2}$ (of size: $12 \mathrm{~nm}$ ) particles on mechanical, thermal and electrical performance of EPDM, SiR and epoxy composites. Moreover, Khattak et al. [22,32-34], studied the longterm multi-stress accelerated aging of HV nano composites.

The first commercial nano-composite of 6-polyamide/montmorillonite was prepared by Toyota with improved mechanical features [35]. Much effort has been made to investigate the effect of filler type, size and concentration on the properties of base material for desired applications [36]. Generally, incorporation of these fillers (alumina, silica, ATH) into polymer matrix varies from 1 to $80 \%$ by weight [37].

In addition, there is increasing trend in preparation and characterization of hybrid (mixture of micro \& nano particles) composites [38-40]. As the polymer insulator service condition in different areas/ countries varies, therefore no monotonous and mature test technique is available [41]. However, various material properties (mechanical, thermal, electrical), weathering, tracking/erosion and water immersion-resistance of polymer insulants can be evaluated by various characterization and analysis methods. This includes scanning electron microscopy(SEM), visual observation, hydrophobicity, leakage current, Fourier Transform Infra-red spectroscopy (FTIR) and Inclined Plan Test (IPT) [42-44].

Moreover, it is pertinent to mention that the impact of individual filler has been widely investigated with only few studies about polymer hybrid (micro/ nano- $\mathrm{SiO}_{2}$, micro-ATH/nano-SiO ${ }_{2}$ and micro-ATH/ micro-SiO ${ }_{2}$ co-filled particles) composites [45]. Limited research has been conducted to examine the combined effect of ATH and $\mathrm{SiO}_{2}$ particles (hybrid) on SiR properties. Silicon rubber composite-dielectrics are comparatively new, their long term performance (mechanical, thermal and electrical) and expected lifespan under contaminated and multi-stress environment is not well-known, which needs to be addressed and investigated. Active research is going on to prepare and characterize new SiR-blends to improve their electrical, mechanical, thermal, erosion/tracking-resistance and water immersion-resistance properties over long-term weathering. Therefore, the practical knowledge and in-depth investigations of HV SiR composites is necessary for electrical professionals in the power field.

This article highlights the most recent research work and characterization results relating to particles (micro/nano-sized) filled polymer insulants used for HV insulations. Moreover, possible future work concerning improved mechanical, thermal, electrical, tracking/erosion and aging performance of polymer composites suggest promising concepts for HV insulation applications (large motors, generators, transformers and other electrical devices).

\section{COMMON FEATURES AND APPLICATIONS OF SILICONE MATERIAL}

By resemblance with ketones, the name "silicone" was given in 1901, by Kipping to describe new composites of the brut formula $\left(\mathrm{R}_{2} \mathrm{SiO}\right)_{\mathrm{n}}$. These composites were quickly recognized as being polymeric and in fact analogous to Polydialkylsiloxanes. Commercially, silicone insulants have been fabricated since 1940s, which are generally non-reactive, stable, resist severe environmental conditions and maintain useful properties over a wide range of tem- 


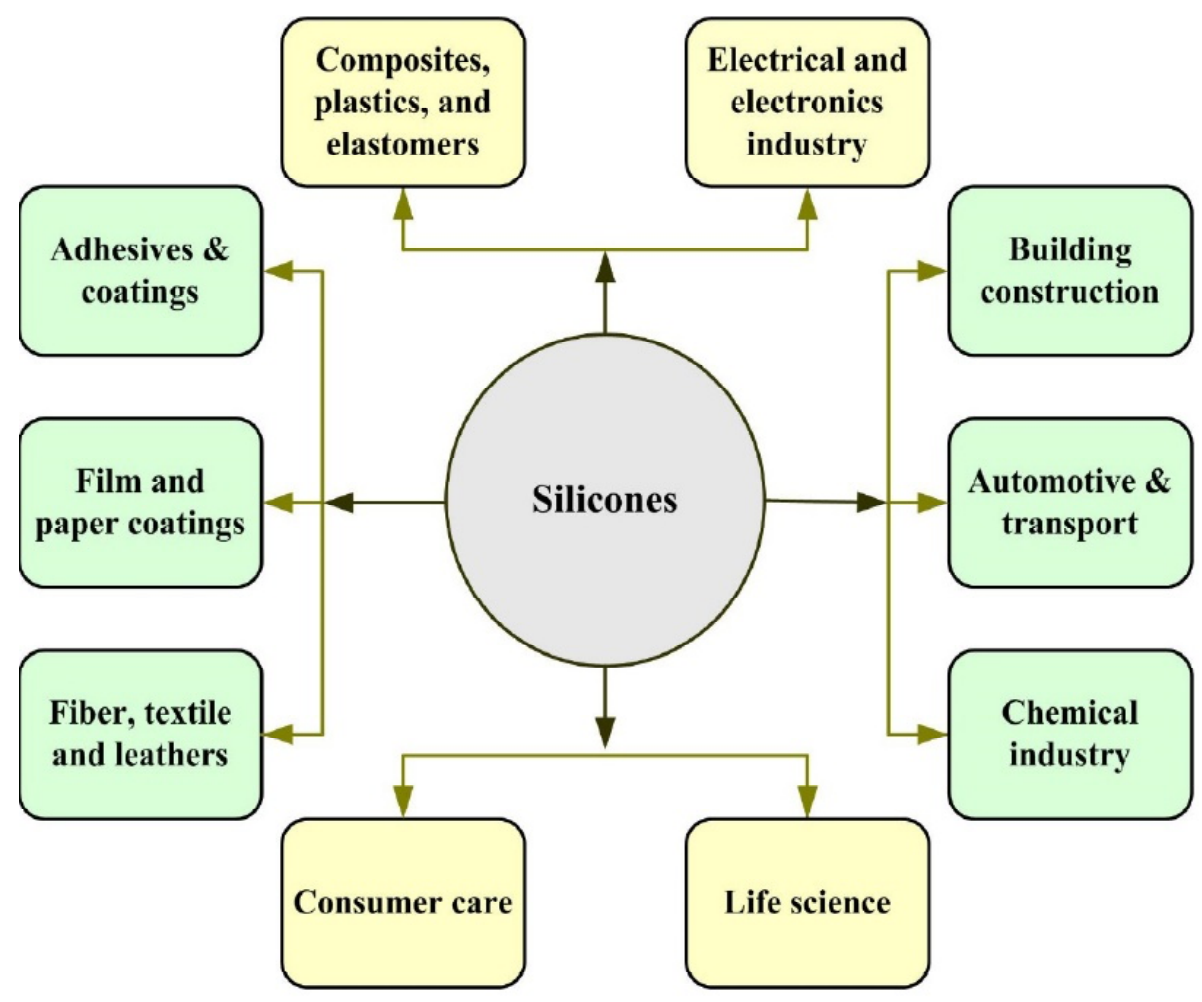

Fig. 1. Silicones applications.

peratures, i.e., from $-55^{\circ} \mathrm{C}$ to $+300^{\circ} \mathrm{C}$ [46-48]. These properties make silicone rubber a good choice for HV insulation, building construction, aerospace, cosmetics and transportation industries.

The properties of silicone rubber like thermal stability, anti-oxidation and weathering comes from Si$\mathrm{O}$ bond strength in their polymer structure. Likewise, due to low surface energy, silicone insulants exhibit features of both organic and inorganic materials, which results in numerous benefits compared to other organic elastomers [49]. The binary nature of silicone has remarkable consequences for particle (filler) interaction in polymer matrix. In order to impart mechanical, thermal and other properties, Silicones are commonly loaded with various types of particles [50,51]. According to final properties (electrical, thermal and mechanical) required, other fillers of small size can also be used to modify the interaction between base rubber and filler particles [52,53].

Recently, the reliability and performance of thousands of commodities/products depend in some way on Silicones, like SiR-grease, release agents, antifoam agent, silicone rubbers, sealants, paper coatings, and hydrophobic agents $[54,55]$. For example, in aerospace or industrial applications, silicones are also found to increase the components' life time. Furthermore, the conservation of historical monu- ments and windows/bathroom seals can be improved by silicone coatings [56].

Telecommunications and electronics industries also need silicone for solar cells, wafers, and optical fiber manufacturing. The general applications of silicone materials are summarized in Fig. 1 [24,57]. On the basis of curing temperature, silicone rubbers are classified into two types: Low viscosity silicone rubber, named as room temperature vulcanizing silicone rubber (RTV-SiR), and high viscosity silicone rubber, i.e. high temperature vulcanized (HTV) SiR. RTV-SiR is extensively used for coatings on ceramic surfaces to enhance their hydrophobicity, whereas HTV-SiR is used for the production of sheaths/weather-sheds of composite insulators [58,59].

Moreover, HTV is cured at high-temperature and pressure by hydrosilylation, whereas RTV is cured at low temperature (room temperature) by condensation reaction. RTV contains cyclic low molecular weight (LMW@5 wt.\%) poly-di-methyl-siloxane (PDMS), while HTV has cyclic and linear LMW (@ 3 wt.\%) poly-di-methyl-siloxanes. Therefore both HTV and RTV impart different reinforcements to various properties of insulants [60,61]. Moreover, to enhance the long-term performance of ceramic insulators, RTV-silicone coatings are applied to HV ceramic insulators [58]. 
Basically, silicone rubbers have high insulation resistance ranging from $1 \mathrm{~T} \Omega$ to $100 \mathrm{~T} \Omega$. The insulating properties of silicone rubber remains stable over a wide range of temperature as well as frequency. There is almost no change in the performance of insulator even when immersed in water which makes silicone rubber ideal for insulating materials. In addition, it offers a good corona resistance when exposed to high voltages. Hence, by exhibiting higher resistance at high voltages and under extreme environments, silicone rubbers are widely used as insulants for high voltage applications [62].

\section{SILICONE CHEMISTRY}

In chemical composition silicone rubbers are quite different from other polymers having no predecessors. Moreover, its effective use cannot be based upon experience, but needs appropriate understanding of its basic chemistry. Primarily, silicone rubbers are based upon rings, networks and chains of alternative oxygen and silicon atoms of siloxane structure. This unique structural property differentiates the silicones from other natural, organic, synthetic and rock-oil, which are fundamentally based on carbon (C) atom chains [63].

The backbone of $\mathrm{SiR}$ is siloxane bonds (-Si-OSi-O-), which are highly stable (with $433 \mathrm{~kJ}^{\mathrm{mol}}{ }^{-1}$ bond energy) than $\mathrm{C}-\mathrm{C}$ bonds ( $\left.355 \mathrm{~kJ} \cdot \mathrm{mol}^{-1}\right)$ of other petrochemicals. Additionally, other reason of silicone stability is lower electronegativity than $\mathrm{C}$, which leads to strong intermolecular interactions due to highly polarized Si-O bonds $[64,65]$. Furthermore, the rings, networks and chains configuration of siloxane in SiR is analogous to silicone (Si) and oxygen $(\mathrm{O})$ structure found in silicate minerals and silica $\left(\mathrm{SiO}_{2}\right)$ particles. This siloxane (-Si-O-) chain assigns inorganic features to SiR insulants. However, it should not be supposed that due to analogy with silica, Si should exhibit porcelain or quartz like chemical stability [66, 67].

\subsection{History of SiR chemistry}

The evolution of silicone chemistry includes several principal steps. In 1824, it was discovered by Berzelius from the reduction of potassium fluorosilicate with potassium:

$$
4 \mathrm{~K}+\mathrm{K}_{2} \mathrm{SF}_{6} \rightarrow \mathrm{Si}+6 \mathrm{KF} \text {. }
$$

Further reaction of silicon with chlorine gave a volatile compound, later identified as tetrachlorosilane $\left(\mathrm{SiCl}_{4}\right)$ :

$$
\mathrm{Si}+2 \mathrm{Cl}_{2} \rightarrow \mathrm{SiCl}_{4} \text {. }
$$

Moreover, in 1863, the next step was made by Friedel and Craft, with the synthesis of the first silicone organic compound, tetraethylsilane:

$$
2 \mathrm{Zn}\left(\mathrm{C}_{2} \mathrm{H}_{5}\right)_{2}+\mathrm{SiCl}_{4} \rightarrow \mathrm{Si}\left(\mathrm{C}_{2} \mathrm{H}_{5}\right)_{4}+2 \mathrm{ZnCl}_{2}
$$

In 1871, Ladenburg observed that in the presence of a diluted acid, the diethyl-die-thoxy-silane, $\left(\mathrm{C}_{2} \mathrm{H}_{5}\right)_{2} \mathrm{Si}\left(\mathrm{OC}_{2} \mathrm{H}_{5}\right)_{2}$, gave an oil that decomposed only at a very high temperature [68,69]. In 1940, Muller and Rochow independently discovered how to react silicone with methyl chloride gas $\left(\mathrm{CH}_{3} \mathrm{Cl}\right)$ to form liquid methyl-chloro-silanes. Their findings provided the starting materials for industrial manufacturing of silicones and initiated a global boom in silicone production. Moreover, in 1947 the WACKER became the first European company to start exploring rubber field. In the subsequent years, WACKER developments laid the keystone for the current and efficient manufacturing of organo-chloro-silanes and silicone products.

In addition, silicones known to chemists as polydiorgano-siloxanes, have a structure that resembles quartz modified with organic groups. They consist of an inorganic backbone built up of alternating silicon and oxygen atoms. The other two bonds of the silicon atoms are occupied with organic groups (preferably methyl), which are responsible for silicones semi organic nature. Hence, in terms of functionality Si structural units can be classified into the following five different units (Fig. 2) $[63,70,71]$ :

a. Zero-functional unit (Tetra-methyl-silane group): It has no reactive element, therefore exhibits zero functionality to build a polymer.

b. Mono-functional unit (Tri-methyl-siloxy group): It acts as terminal group or chain blocking group, but not propagating like di-functional group.

c. Di-functional unit (di-methyl-siloxy group): This group forms the backbone (important chain builder) in methyl-polysiloxanes, which extends cyclic or linear polymers but does not terminate macromolecular chains and ring compounds.

d. Tri-functional unit (mono-methyl-siloxane group): This group not only enlarges a ring or extends a chain, but also produces branched molecules and forms the basis of resins (crosslinking). e. Tetra functional unit (zero methyl-siloxane group): In structure, this unit resembles with silica structure, which is capable of creating two-branches or extending polymer chains. Moreover, it maintains its structure whether occurs in quartz crystal or cross-linked SiR. 


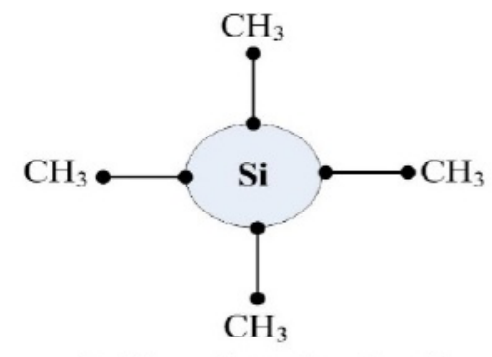

A: Zero-functional unit (Tetra-methyl-silane group)

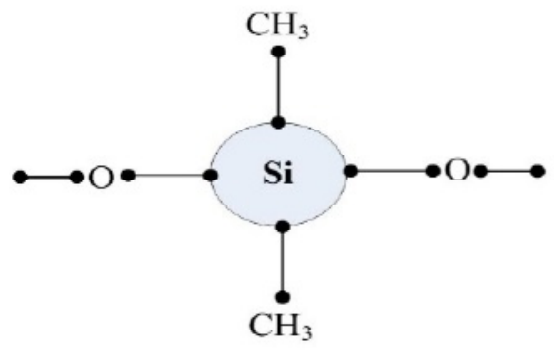

C: Di-functional unit (di-methylsiloxy group)

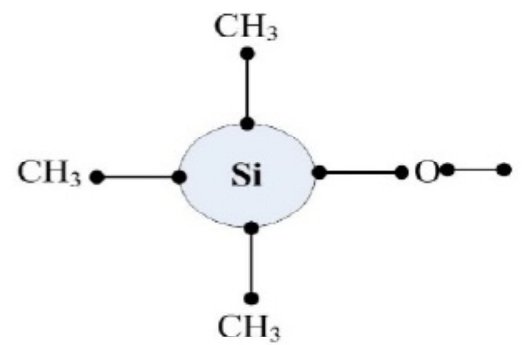

B: Mono-functional unit (Tri-methyl-siloxy group)

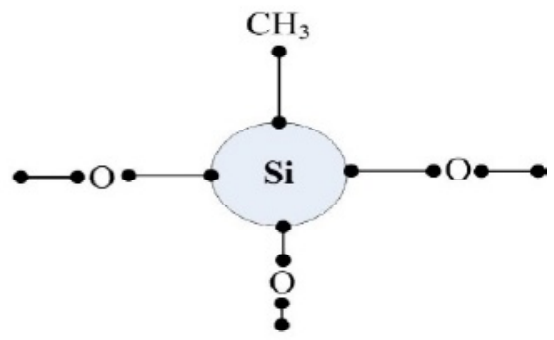

D: Tri-functional unit (mono-methylsiloxy group)

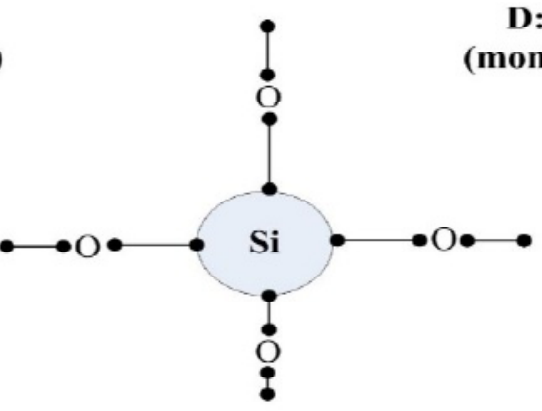

E: Tetra-functional unit (zero-methylsiloxy group)

Fig. 2. Silicone structural variety.

From the above discussion it is obvious that only four functional units of $\mathrm{Si}$ are capable of constructing organo-siloxane polymers. Moreover, among the above functional units, the moderate molecular weight cyclic and linear chain-blocked polymers are found in liquids, whereas high-molecular-weight (HMW) linear compounds are elastomers. In addition, the Si cross-linked polymers based on tetrafunctional or tri-functional units are found resinous $[63,72]$.

\subsection{Factors effecting SiR chemistry and properties}

Structurally, there are two factors which are responsible for chemical instability of silicone polymers: the less cross-linked siloxane chain, and organic groups of silicone polymer. Additionally, the more exposed parts of SiR are also susceptible to many reactions. It follows that stresses (chemical, electrical, environmental) which influence the Si-O bond of silicone polymer, will disintegrate (break up) the $\mathrm{SiR}$ backbone. For instance, the hydro-fluoric-acid will vaporize the organo-fluoro-silanes fragments and de-polymerize the silicone polymers. Furthermore, alkalies will also destroy the organo-silicones chains of silicone by forming alkali salts.

Moreover, the addition of organic/inorganic groups into silicone polymer will vary the curing, dielectric strength, solubility, flexibility, resistance to erosion/ tracking and oxidation characteristics. For instance, larger the alkyl-groups in alkyl-siloxane polymer; lesser will be its oxidation resistance. Consequently, softer will be the resin.

Likewise, the impact of temperature on physical properties of aryl-silicones are greater compared to methyl-siloxanes. The reason is that compared to aryl-silicones, the naturally methyl-group adds less amount of $\mathrm{C}-\mathrm{H}$ bonds and has no $\mathrm{C}-\mathrm{C}$ bonds, therefore methyl-poly-siloxanes exhibit unique properties $[73,74]$. 


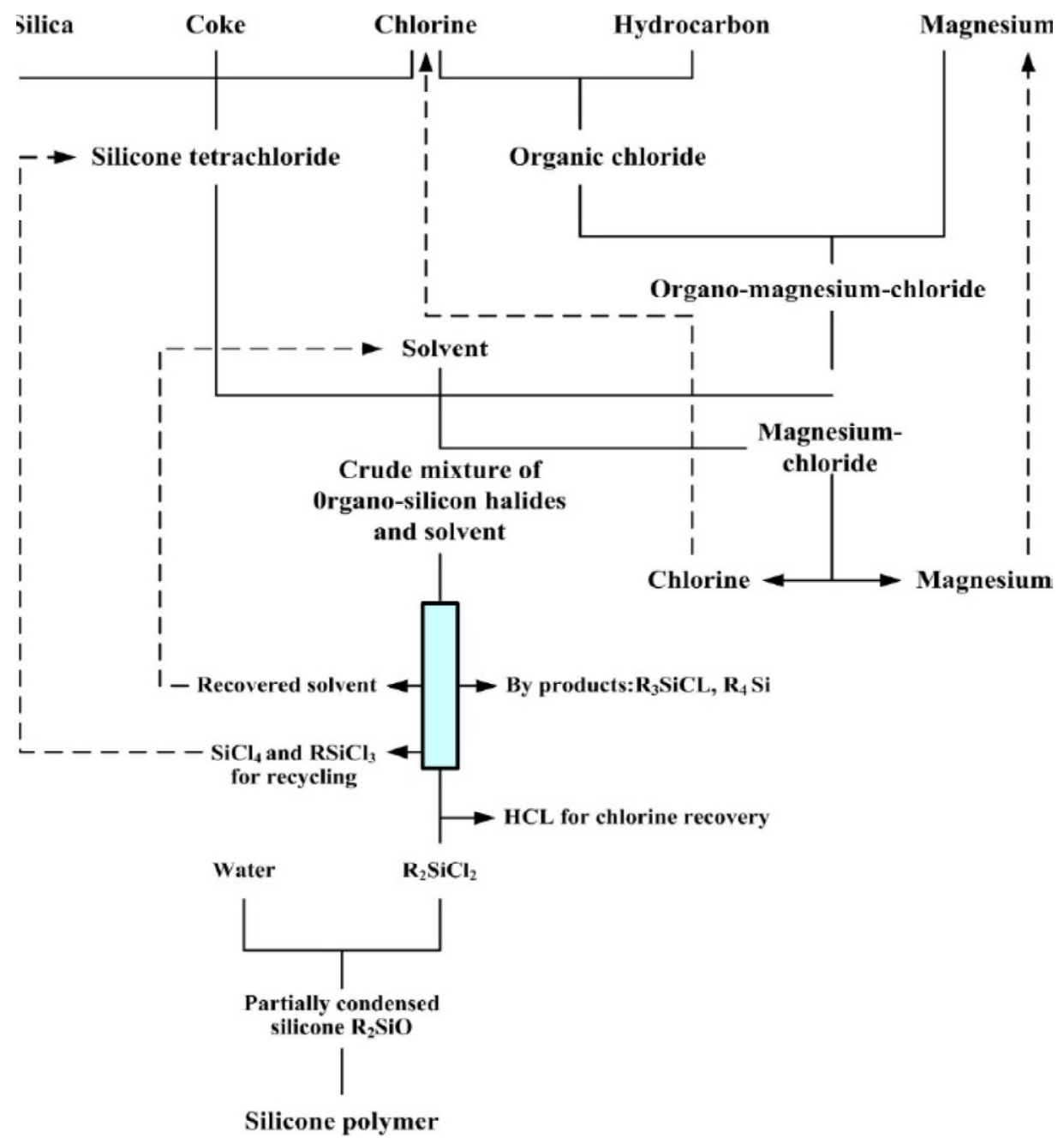

Fig. 3. Silicone polymer production: Grignard procedure.

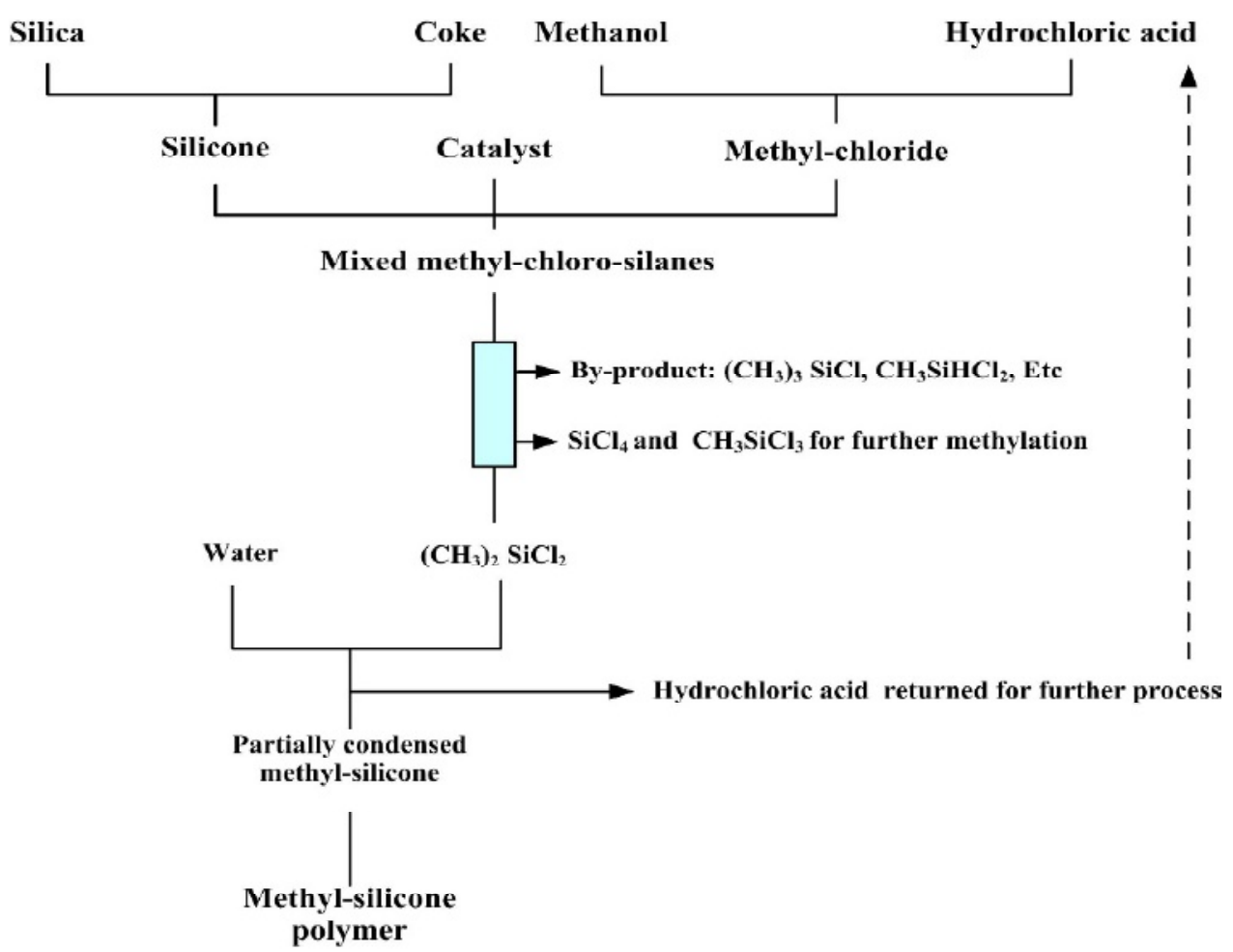

Fig. 4. Direct method: Methyl-silicone polymer production. 


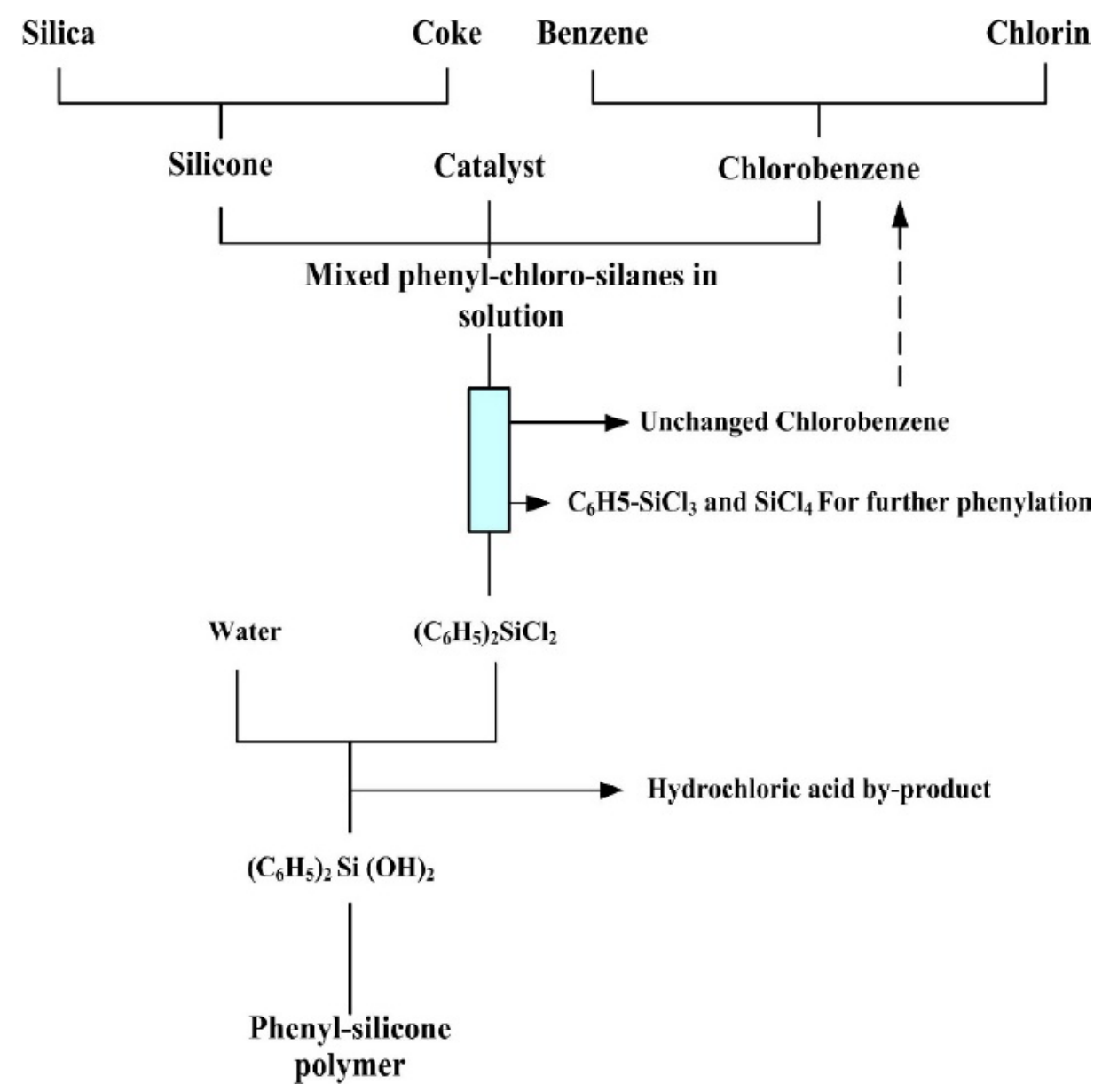

Fig. 5. Direct method: Phenyl-silicone polymer production.

\subsection{Silicone polymerization}

There are various techniques for production of $\mathrm{Si}$ polymers. Methyl, ethyl or any other alkali group's polymer with silicone can be achieved using the guidelines of the following important methods as summarized in Figs. 3, 4, and 5 [63,75,76].

a. Grignard method

b. Direct method

Moreover, all types of silicone polymerization comprises four basic steps as follows [77],

- $\mathrm{SiO}_{2}$ reduction to $\mathrm{Si}$

- Chloro-silanes synthesis

- Chloro-silanes hydrolysis

- Polymerization and poly-condensation.

\section{SILICONE RUBBER PROPERTIES ENHANCEMENT BY ADDITION OF FILLERS}

Under wet operating conditions (i.e. heavy fog, moisture, and acid rain etc.) pure SiR insulators suffer from hydrophobicity-loss, weak tracking and erosion-resistance, surface deterioration, and poor mechanical, thermal and dielectric properties. The loss and recovery of hydrophobicity in silicone rubber has been the subject of several research works [78]. Moreover, to improve the performance (mechani$\mathrm{cal}$, thermal and electrical properties) of polymer insulants, micro/nano-sized particles (such as silica, quartz, ATH etc.) have been added into polymer matrix [79]. According to the literature, extensive research has been conducted to investigate the influence of size, shape, concentration, dispersion and type of filler on the characterization of silicone rubber insulants [11,80-82].

Ghunem et al. [83] studied the impact of ATH and $\mathrm{SiO}_{2}$ on dry-band-arcing suppression of silicone rubber using leakage-current wavelet-based multiresolution analysis. They found that by addition of ATH or silica, the thermal-conductivity of SiR increases, thereby delaying the eroded temperature. Jun-Wei et al. [84] reported the impact of hybrid fillers (micro- $\mathrm{Si}_{3} \mathrm{~N}_{4}$-nano- $\mathrm{Al}_{2} \mathrm{O}_{3}$ ) on mechanical, thermal and dielectric properties of SiR composites.

In literature, various experimental techniques have been reported to investigate the effects of $\mathrm{SiO}_{2}$ characteristics (i.e. silica grade, type, surface treatment, loading \& dispersion) on properties of natural 


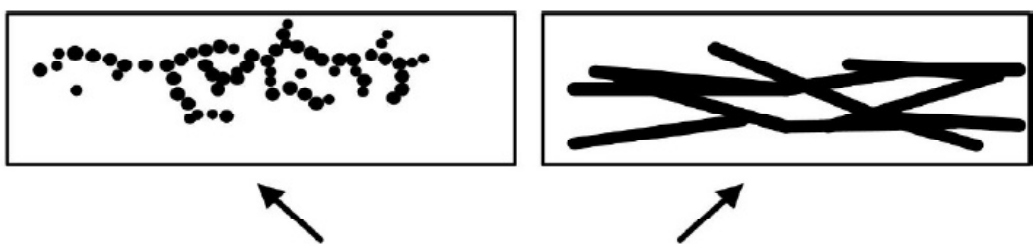

Percolation threshold

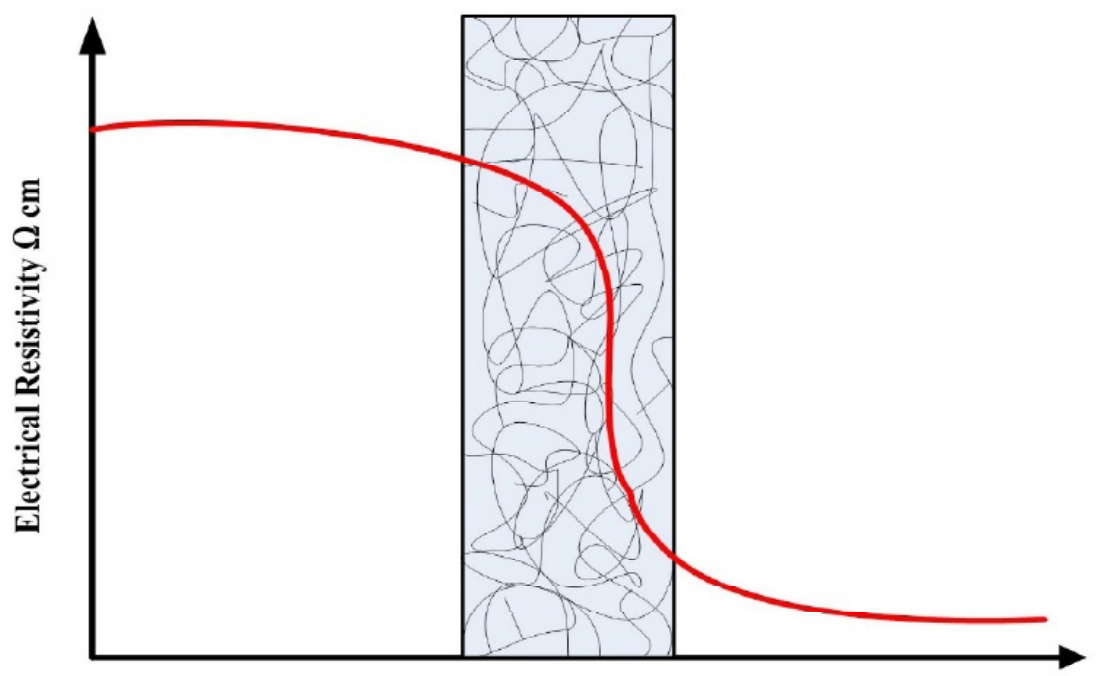

Filler Content

Fig. 6. Polymer resistivity relative to conductive filler content (Redrawn and adapted figure from [84]).

and synthetic rubber composites $[34,85,86]$. Other researchers correlated silica loading with erosion suppression of polymer composites [87,88]. Moreover, majority of polymer insulators are non-conductive, but in some applications conductivity in needed for electrostatic charge-dissipation.

In addition, to fabricate the conductive polymers, conductive-type of micro/nano particles can be incorporated into polymer matrix. For known quantity of conductive particles called percolation-threshold, a stable and continuous-network of fillers is formed across the polymer matrix. Consequently, the material undergoes abrupt changes from insulator $\left(>10^{10}\right.$ $\mathrm{Wcm})$ to conductor $\left(<10^{5} \mathrm{Wcm}\right)$ state as demonstrated in Fig. $6[61,89,90]$. Additionally, the in- creased molecular interaction between polymer matrix and fillers enhances thermal degradation and stability. Secondly, the amalgamation of inorganicfillers reduces the quantity of polymer materials thereby reducing the overall cost [91].

In addition, for some applications, coupling-agent can be used to enhance the interaction between fillers and base polymer thereby enhancing the material properties [92]. The commonly used inorganic particles that can be incorporated into rubber matrix are listed in Table 1 [93-97].

Besides, the properties variation of micro/nano composites by various parameters (filler type, size and loading), the fillers improper-dispersion in the improvement of composites properties is often cited

Table 1. In-organic fillers and their role in insulator characterization.

\begin{tabular}{ll}
\hline Particle type & Property modification \\
\hline $\mathrm{Al}_{2} \mathrm{O}_{3}$ & Anti-tracking, anti-erosion and thermal-conductivity \\
$\mathrm{SiO}_{2}$ & Anti-tracking, anti-erosion and thermal-conductivity \\
$\mathrm{TiO}_{2}$ & Photo-catalytic, relative-permittivity and thermal-stability, \\
$\mathrm{Varistor}(\mathrm{ZnO})$ & Mechanical property, electrical-conductivity, permittivity \\
$\mathrm{CaCO}_{3}$ & Flame retarding, hydrophobicity \\
$\mathrm{BaTiO}_{3}$ & Relative permittivity, thermal stability \\
$\mathrm{Al}_{2} \mathrm{O}_{3} \cdot 3 \mathrm{H}_{2} \mathrm{O}$ & Thermal conductivity \\
$\mathrm{Sb}_{2} \mathrm{O}_{3}+\mathrm{SnO}$ & Electrical conductivity \\
\hline
\end{tabular}


as a key diminishing-factors [98-101]. Hence, to enhance the filler-dispersion in polymer matrix, different mixing-procedures such as physical and chemical dispersion techniques can be adopted.

\subsection{Physical-dispersion techniques}

For fillers dispersion in polymer matrix, the physical-dispersion techniques include ultrasonic-agitation and conventional mechanical-mixing. In ultrasonic-agitation, the vibrations releases trapped gases by avoiding the development of voids in the composite matrix, whereas mechanical-mixing is obtained by applying the shear-force to stimulate the particle-surface, physico-chemical properties and changing the external crystal-structure. The only advantage of such techniques are the use of limited extra-additives. Moreover, characteristically simple mechanical-mixing is not suitable for homogeneous filler dispersion: because during mixing, the breaking of some large particles (larger than $1 \mu \mathrm{m}$ ) into small one may occur in a short-time. Consequently, further particle-dispersion cannot be achieved. Another flaw of such methods are the base-polymer degradation due to shear-heating.

\subsection{Chemical-dispersion techniques}

Such techniques of filler dispersion depend on the existence of auxiliary-additives to vary the fillers surface properties, which includes both chemical and physical modifications. Physically some macromolecule-chemical-additives are used in liquid form to cover or absorb the micro/nano particles and hinder the fillers agglomeration. Moreover, for physical-surface modification, the surfactants and dispersants are common chemical additives. Due to the dissociation process, the dispersants are electrified and absorb into the particle-surface thereby changing the fillers surface-characteristics. Consequently, it improves the surface-potential in such a way that the repulsive forces becomes stronger between particles [91,102].

Among the particles when the repulsive-forces becomes greater than the attractive-forces, the disintegration of filler agglomeration may take place. Additionally, with in the same molecule the surfactants can be characterized by hydrophobic and hydrophilic chain-segments [103]. The authors of [104], used Triton-TM-X-100 (Triton)-surfactant for nano-silica surface modification, thereby enhancing the particle-dispersion in the RTV-SiR polymer matrix, which was confirmed by the SEM-images and reduced eroded-mass.
Tee et al. [105] used the conductive-nano-silver (which was treated by silane coupling agent) with epoxy to develop epoxy-nano-composites. They found that treated nano-silver $(\mathrm{Ag})$ exhibited outstanding flexural and electrical properties compared to un-treated samples. Hence, it can be inferred that polymer composites with surface-modified micro/ nano-particles has led to improved properties relative to un-treated particles. Furthermore, to attain the desired results, the selection and optimum concentration of chemical-additives must be carefully controlled.

\section{COMPOSITE MATERIALS}

In this modern age of science and technology, the composite material science and engineering play a vital role [106]. Composite materials can be defined as: the mixture of two or more materials, working together in such a way so as to produce a compound with enhanced properties (mechanical, thermal and electrical). Examples are, steel-reinforcedconcrete, glass reinforced polymer, straw in baking-bricks, fiber embedded in other material matrix and carbon/silica-reinforced polymers [107].

Composites consist of host matrix (base-material) and one or more filler particles. The composites having one filler particle referred to as binarycomposites, whereas, composites having two filler particles are referred to as ternary-composites and so on. The prefix micro/nano just denotes particle size. Furthermore, in composite materials the filler size and shape are the key parameters which modify the host matrix characteristics (i.e., mechanical, thermal and electrical properties) [108].

However, the cause of these enhancements are not yet fully explored. Therefore, the influence of micro/nano-fillers on characterization of polymeric materials have been investigated [109]. Moreover, composites are commonly classified into two types. The first type refers to host-matrix constituent, whereas, type- 2 is based on reinforcement form (filler type) as summarized in Figs. $7 a$ and $7 b[110,111]$. In addition, the historical context and relative importance of metals, ceramics, composites and polymers have been presented by Ashby as shown in Fig. $8[107,112]$.

In electrical engineering, the use of composites is not new, and their most common application includes HV polymer insulants. A polymer composite-insulator refers to a micro/nano-composites, with SiR/EPDM/Epoxy as host matrix and micro/nanosized particles as filler. 


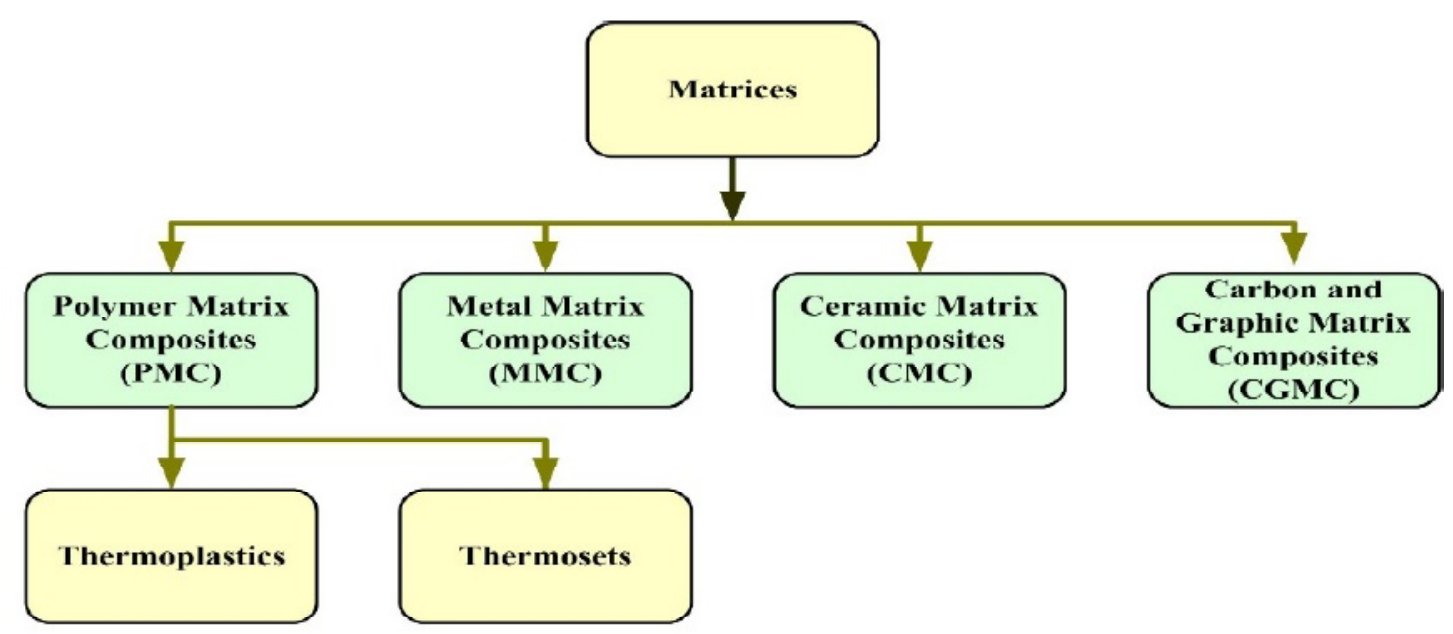

(A)

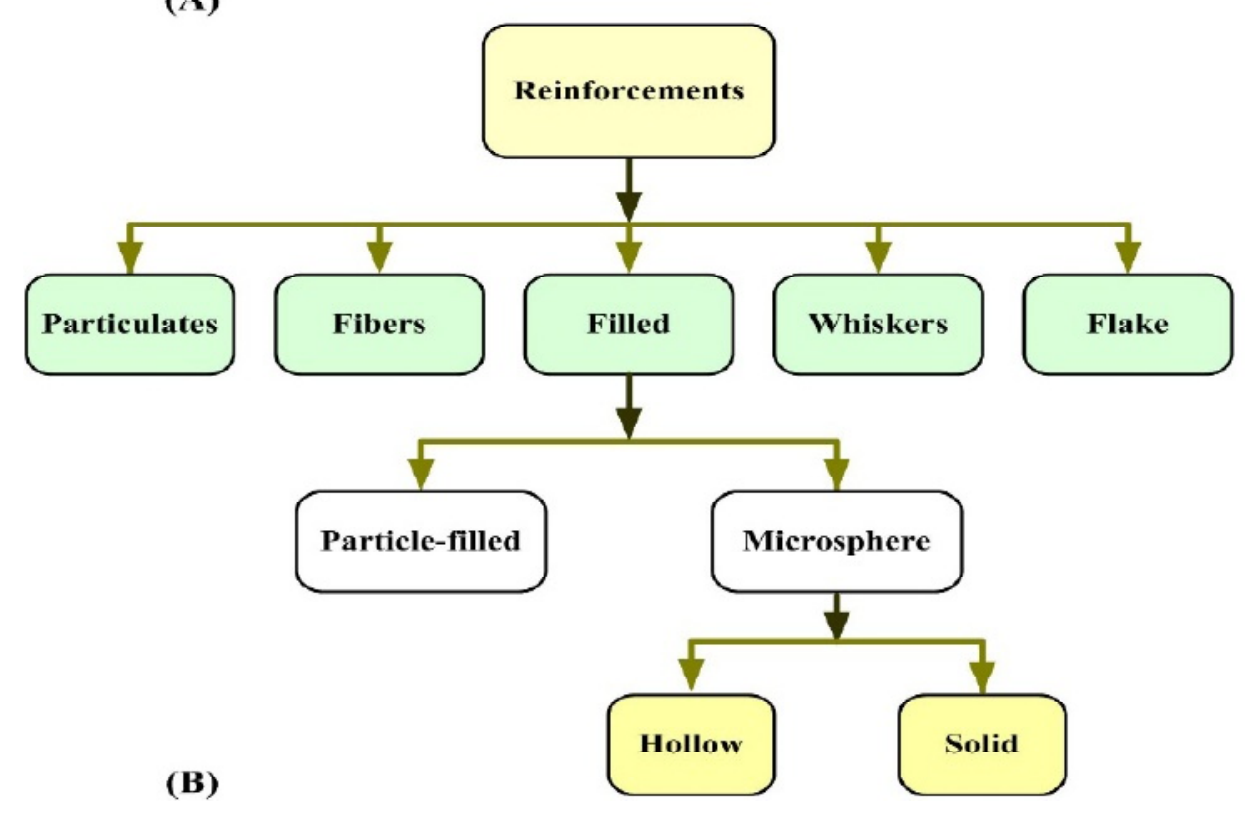

Fig. 7. A: Type 1 on the basis of matrix, B: Type.2 on the basis of reinforcements.

However, the main purpose of using particles in polymer insulators are to enhance their thermal, mechanical and electrical properties. In both laboratory and field testing, considerable improvements in their properties have been described, but actual reason is still a challenge to be identified $[113,114]$. Therefore, in this research, both binary and ternary polymer composites, filled with $\mathrm{ATH}$ and $\mathrm{SiO}_{2}$ are prepared and comparatively investigated for various characteristics.

\subsection{Materials classification}

\subsubsection{Engineering materials}

In material science/engineering, the various factors which form the base of numerous physical systems are: (i) material chemical composition, (ii) material occurrence mode, (iii) compounding and the refin- ing process, (iv) material crystalline and atomic structure and $(v)$ material technical and industrial use [115].

However, within the scope of engineering and material science, the common engineering materials may be categorized into one of the following groups [116]:

- Alloys and metals

- Organic/inorganic polymers

- Semiconductors

- Advanced-materials

- Bio-materials

- Ceramics

- Composites

\subsubsection{Polymeric materials}

Polymeric-materials are the diversified sets of engineering-materials which are the core constituents 


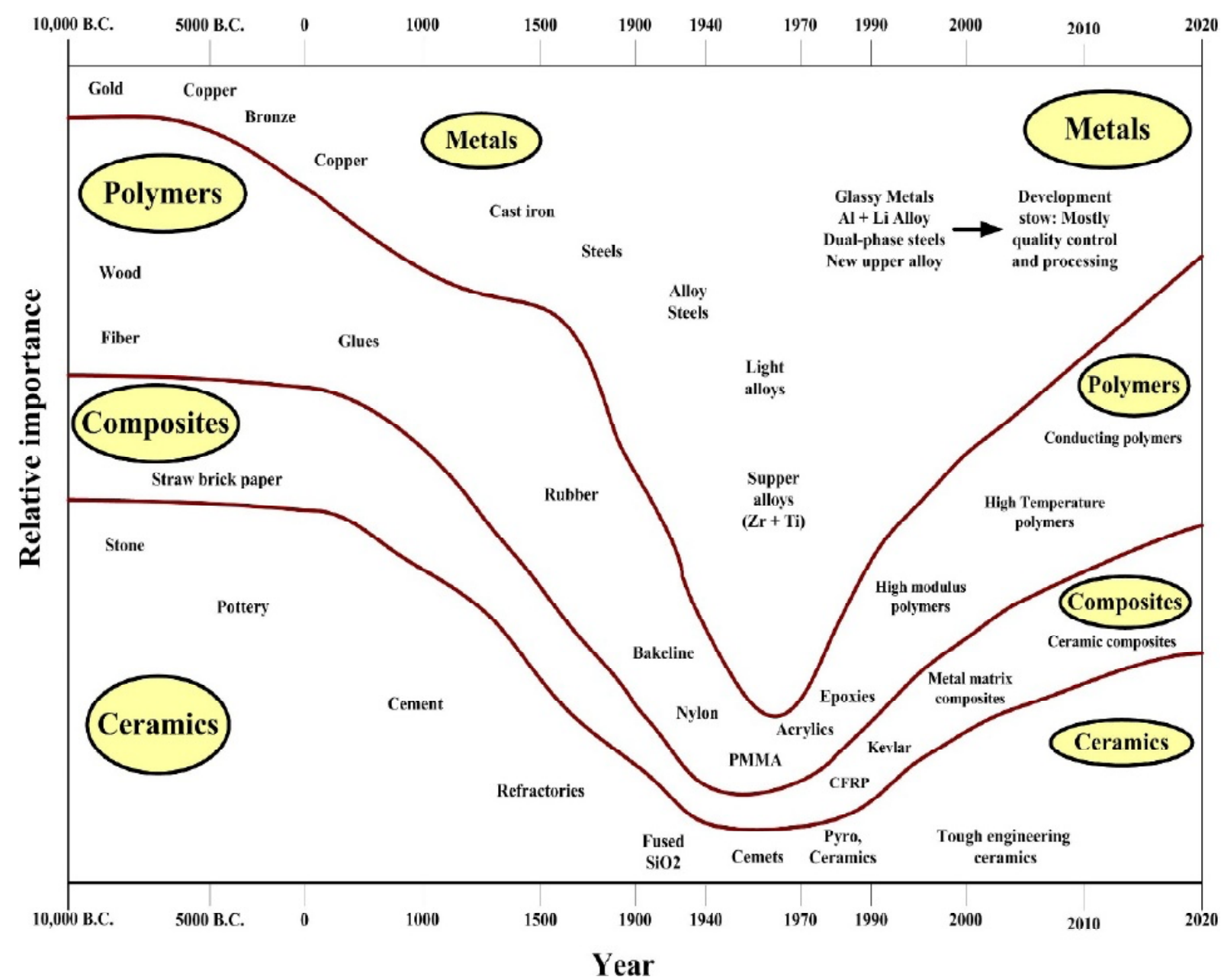

Fig. 8. Historical background of different materials (Redrawn and adapted figure from [107]).

of paints, plastics, resins, rubbers and adhesives. Mostly polymers are organic in nature (i.e. containing carbon), comprise of large molecules: each consist of various atoms. Examples are the polyamides (PA), poly-vinyl-chloride (PVC) and polyethylene resins, etc. Moreover, few commonly used polymers for engineering applications are summarized in Table 2 [117].

Furthermore, based on their application performance polymeric materials can be classified into four groups [118].
Commodity insulants, comprise polyethylene, copolymer, polystyrene, cellulose nitrate, polyvinyl chloride, styrene-acrylonitrile-copolymer, un-saturated-polyester and bismal-eimide. These materials have low cost, inferior characteristics and performance, large-consumption and extensive applications.

Intermediate insulants, include acrylic (polymethyl-methacrylate), modified poly-phenylene-oxide, polyolefin-thermo-plastic-elastomer, melt-

Table 2. Polymeric materials.

\begin{tabular}{llll}
\hline Polymer & Abbreviation & Polymer & Abbreviation \\
\hline Polyethylene & PE & Polytetrafluoroethylene & PTFE \\
Polypropylene & PP & Poly (vinyl fluoride) & PVF \\
Polystyrene & PS & Poly (vinyl chloride) & PVC \\
Polybutylene & PB & Poly (vinyl acetate) & PVAC \\
Poly(methylmethacrylate) & PMMA & Polyacrylonitrile & PAN \\
Polyisoprene rubber & IR & Epoxy & EP \\
Silicone polymer & Si & Polyurethane & PUR \\
\hline
\end{tabular}


processible-rubber, thermoplastic-vulcanizate, polypropylene, thermoplastic-elastomers (TPE), high impact polystyrene, and glass fiber reinforcedpolypropylene and so on. Additionally, compared to commodity insulants, these polymeric-materials have better thermal, mechanical and electrical properties.

Engineering-thermoplastics, comprise of polyamide, polyacetal, polybutadiene, polycarbonate, polyethylene-terephthalate, liquid-injection-silicone, and block-copolyester, etc. Moreover, as engineering materials, these materials exhibit random mechanical properties compared to other groups.

High-performance engineering-materials, retain a higher tensile strength at elevated temperatures. In the presence of moisture, gases, acids and polluted environment, they maintain higher electrical properties without degrading chemical properties. In addition, the high-performance-insulants are inherently flame-retardant with higher resistivities. These materials comprise high-temperature-nylon, poly-sulfone, liquid-crystal-polymers, polyphenylene-sulfide, silicone-polymers and fluoro-polymers.

Furthermore, to capture the market window, competition among polymer producers has created more than 26,000 resin-grades thereby providing several choices to meet the end-user's application requirements.

\subsubsection{Engineering requirements of polymer insulants}

Recently, as engineering-materials, polymer composite insulants have gained considerable attention of researchers. However, in strength and temperature resistance, polymeric-materials are inferior to metallic-materials. Moreover, due to superior performance in contaminated and corrosive conditions, polymeric insulants are replacing ceramic and glass materials. For example, small gear-wheels made of steel are now substituted by Teflon and Nylon dielectrics.

Therefore, before designing a component or selection of materials for a particular application, one must know their operational requirements (mechanical, thermal and electrical), limitations, availability of raw materials, cost, and most importantly, availability of alternatives, etc. Moreover, for engineering applications to meet the various requirements, different elements exhibit different characteristics. Therefore, the important properties of polymerinsulants, which prescribe their selection for par- ticular application, are discussed in context of current research as follows [116,118-120].

\subsubsection{Mechanical characteristics}

In the material selection-process and product design, the consideration of mechanical properties of polymeric-materials are very important. Mechanical characteristics of polymer-insulants relies on molecular structure, reinforcements, filler/polymer type, compounding techniques, chemical-additives, amount/type of colorant and crystallinity-rate. Furthermore, manufacturing procedures and testing methods also alters the mechanical properties of polymer insulants. In the USA, more than 26,000, formulations of polymeric-materials are developed [120]. Each formulation has been fabricated according to market requirements with enhanced mechanical properties. However, before design and development of polymer insulants, it is necessary to select the most suitable materials with satisfactory mechanical performance. The significant mechanical characteristics of polymer insulants are [118]:

- Tensile-stress: This property depends on material internal resistance to the applied stress. It can be defined as, "at any given point, the tensile-load applied per unit-cross sectional area".

- Strain: It describes, the ratio of elongation produced due to applied load relative to the original length of a specimen.

- Percentage of elongation: The percent increase in length with respect-to original length of a test specimen.

- Yield point: On the stress-strain curve, the first point at which change in strain occurs without change in stress.

- Elasticity-modulus: Below the proportionality limit, the ratio of stress to corresponding strain of polymeric-materials.

- Hardness: The degree of material-resistance to abrasion, wear, scratching and indentation is known as hardness.

- Ductility: The material elongation before rupturing is known as ductility.

- Impact-strength: To fracture a polymer sample, the energy required per unit-cross-sectional-area is called impact-strength.

- Wear-resistance: It is the ability of an insulant to maintain its physical dimensions under rolling or sliding with other surface/material.

- Corrosion-resistance: The ability of a material to resist the corrosion process, i.e. it takes place at slow rate with time. 


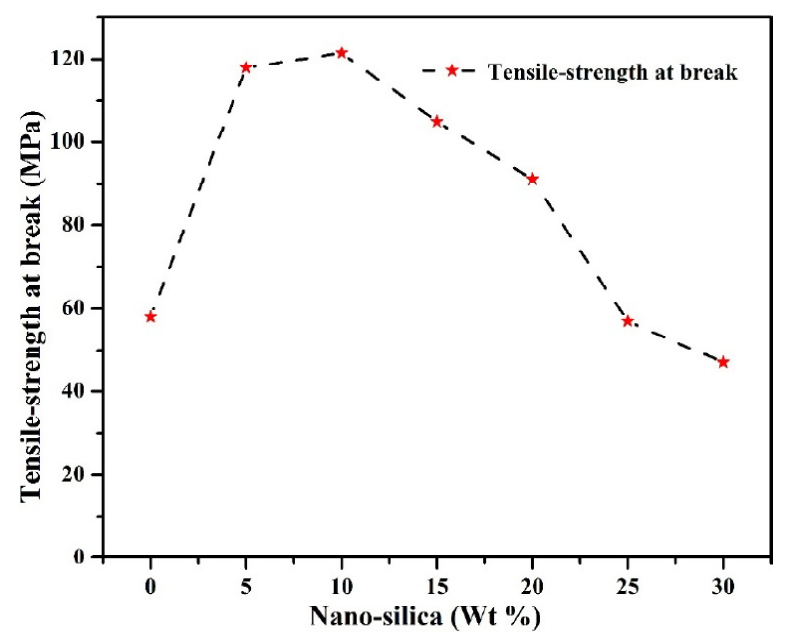

Fig. 9. Tensile-strength of $\mathrm{PA} / \mathrm{SiO}_{2}$ composites.

All these characteristics of polymeric materials vary from formulation to formulation, which also fluctuates due to viscoelastic behavior of polymer insulants.

In past couple of years various studies on mechanical and non-mechanical performance of polymer insulants have been carried out by numerous researchers. To enhance mechanical, thermal and electrical characteristics of polymer insulators, suitable amount and type of inorganic particles like $\mathrm{Fe}_{2} \mathrm{O}_{3}$ [121], $\mathrm{Al}_{2} \mathrm{O}_{3}$ [122], and $\mathrm{ZnO}$, etc., can be amalgamated with base matrix in specific wt.\% [123]. Kemaloglu et al. [124] investigated, that compared to micro-size Barium Nitride (BN) particles, the nanosized BNs have more pronounced impact on mechanical and thermal properties of SiR composites. According to Ramirez et al. [125] there are twenty one reasons to justify the amalgamation of micro/ nano particles into polymer matrix. The main purpose of inorganic fillers are to enhance the physical and electrical characteristics of base resins $[126,127]$.

In the literature a variety of experimental techniques have been reported to investigate the effects of $\mathrm{SiO}_{2}$ characteristics (i.e., silica grade, type, surface treatment, loading \& dispersion) on natural and synthetic latex composites $[34,85,86]$. Some researchers correlated silica loading with erosion suppression of polymer compounds [87, 88]. Likewise, the addition of ATH and silica has been frequently incorporated into SiR matrix to enhance their mechanical properties [128]. In other study, Irwin et al. [129] found significant improvements in elongationat-break, tensile-strength and hardness of polyamide-films. In addition, the tensile-strength of polyamide composites as a function of $\mathrm{SiO}_{2}$ particles demonstrates a non-linear behavior with higher silica concentration (wt.\%) as exhibited in Fig. 9 [130].

Furthermore, to gain physical strength, fumed silica, approximately $2 \mathrm{wt} . \%$ has been incorporated into SiR composites. This reinforcement not only comes from filler size, shape and dispersion, but mostly it comes from molecular interactions [131]. Ramirez et al. [104], reported the influence of mi$\mathrm{cro} /$ nano silica and alumina particles on mechanical (elongation at break, tensile-strength and hardness) and electrical properties of SiR composites. They found that higher silanol-groups play a significant role in the SiR characteristics.

It is studied that particles networked dispersion in polymer matrix can improve their properties (mechanical, surface, electrical) [132]. In other study Zha et al. [133], investigated, the mechanical, dielectric and electrical properties of SiR-blends filled with $\mathrm{Si}_{3} \mathrm{~N}_{4} / \mathrm{Al}_{2} \mathrm{O}_{3}$ particles. To the best of our knowledge limited research has been conducted to examine the combined effect of various micro/nano particles $\left(\mathrm{SiO}_{2}\right.$ and $\left.\mathrm{ATH}\right)$ on SiR mechanical characteristics.

\subsubsection{Thermal characteristics}

The variation in material properties with respect to change in temperature are known as thermal-properties. During normal operation, one can foresee the performance of polymer-insulants by knowing their thermal-characteristics (latent-heat, thermal-conductivity, specific heat, thermal-stress and thermal expansion). For engineering applications these characteristics perform an important-role in material selection [115,134].

As the temperature rises, polymeric insulants tend to enlarge. Moreover, compared to ceramics and metals, the thermal-expansivity (á) of unfilledpolymers are generally higher. They exhibit lower thermal-conductivity compared to metals/ceramics due to lower energy transfer through polymer-networks. Therefore, in foam/fiber-form polymerinsulants are broadly applied for HV thermalinsulations. The thermal-characteristics of some typical-polymers are summarized in Table 3 $[135,136]$. Furthermore, among thermal-characteristics, few can be described as follows [120,134,137]:

- Thermal Conductivity (K): It represents the material ability to transfer certain amount of heat through a unit-area in a unit-time at constant temperature. Quantitatively, copper/aluminium have higher conductivity compared to Bakelite (poor-conductor). So higher the thermal-conductivity, more 
Table 3. Thermal expansivity/conductivity of polymeric-insulants.

\begin{tabular}{lll}
\hline Polymer & Thermal-conductivity $(\mathrm{W} / \mathrm{mK})$ & Thermal-expansivity $\left(10^{6} \mathrm{~K}^{-1}\right)$ \\
\hline PS & 0.181 & 70.1 \\
PC & 0.210 & 60.0 \\
PMMA & 0.180 & 70.0 \\
PVC & 0.170 & 80.0 \\
PP & 0.220 & 150.0 \\
HDPE & 0.510 & 200.0 \\
LDPE & 0.410 & 250.0 \\
PA-6 & 0.290 & 80.0 \\
\hline
\end{tabular}

will be the heat transfer rate through a unit piece of material. Mathematically, thermal-conductivity can be described by the following formula:

$$
\cdot K=\frac{Q . x}{[A .(T 1-T 2) \cdot t]},
$$

where $Q$ is heat flow (K.cal), $x$ is distance between two sides $(\mathrm{m}), t$ is time(s), $A$ is surface-area $\left(\mathrm{m}^{2}\right)$, $T_{1}$ and $T_{2}$ are material hot and cold side temperatures $\left({ }^{\circ} \mathrm{C}\right)$, respectively.

- Specific-Heat (c): It can be defined as, the amount of heat-required to raise the temperature through 1 ${ }^{\circ} \mathrm{C}$ of a homogeneous-material (unit-mass). Actually, it represents the material heat capacity and mathematically it is given be the following equation.

$$
C=C / M \text {, }
$$

where $C$ is heat capacity, $M$ is material-mass and $c$ denotes specific heat.

- Thermal-Expansion: The increase in any dimension (length, width, height) of a solid on heating is known as thermal-expansion. It may be cubical, linear or isotropic. In addition, the increase in length per unit-length per 1-degree rise in temperature is termed as coefficient of linear-expansion.

- Thermal-Resistance (RT): It is the conductor resistance, when heat-flow occurs due to temperature difference between two points of a conductor. Mathematically it is given by the following relation.

$$
R t=\left(T_{1}-T_{2}\right) / H \text {, }
$$

where $T_{1}$ and $T_{2}$ indicate the temperatures $\left({ }^{\circ} \mathrm{C}\right)$ of two points, $\mathrm{H}$ is the heat rate and Rt denote thermal-resistance.

\subsection{Thermal degradation mechanisms of polymer-insulants}

In polymer-chain, the strength of the weakest-bond is the very governing factor which limits its thermal- stability. However, polymer thermal-degradation follows three major processes: de-polymerization, side-group-elimination and random scission [138,139].

a. De-polymerization: It is a free radical process in which polymer is degraded into co-monomers and monomers. Mostly polystyrene and poly-methacrylates are degraded by this mechanism. Moreover, on the backbone of the polymer, the formation of a free-radical causes the polymer to undergo chain-scission and produces small-molecules which moves towards free-radicals. This mechanism (depolymerization) is the reverse process of polymerization (monomers combined to form polymer).

b. Side-group-elimination: Generally elimination of side-groups occurs in two stages. In the firststage, deletion of side-groups from polymer-backbone by leaving an unstable polyene-macromolecule, which further undergoes chemical-reaction (i.e. formation of aromatic molecules, chain-scission into smaller molecules or char formation). For instance, $\mathrm{PVC}$ thermal degradation in first-stage is the formation of $\mathrm{HCL}$ (hydrogen-chloride). A polyene-macro-molecules after first step of PVC thermal-degradation, undergoes further reactions which yields toluene, naphthalene and benzene.

c. Random-Scission: This mechanism includes generation of some free-radicals on the backbone of polymer, which produces a series of small recurring oligomers of different chain-lengths. Generally, polyethylene polymer decomposes into few pieces, which further split into smaller fragments and so forth. Hence, it is obvious that without the formation of monomers (free molecules), the polymerization process can be reduced.

Moreover, fragmentation of polymers can be stimulated by radiation, chemical, thermal or mechanical excitation. Regardless of mechanism, three forms of bond-cleavage takes place, which may be $\mathrm{C}-\mathrm{C}$ bonds breaking, backbone-breaking and shifting of 1/3-hydrogen which leads to unsaturated or 
saturated end-groups. Additionally, consequent to such random-scission, a weight-loss with final degraded-products may happen in polymer insulants [140].

In the following, literature review regarding thermal degradation and influence of particles (fillers) on thermal characteristics of polymeric-dielectrics is provided:

Recently, numerous researchers have studied thermal degradation and their resistance to erosion and tracking of SiR composites. They found that material degradation depends on arc mobility and leakage current magnitude [141]. Moreover, at high temperature $\left(350^{\circ} \mathrm{C}\right.$ for pure SiR), thermal degradation of $\mathrm{SiR}$ composites are de-polymerization and formation of low molecular weight (LMW) components, which varies with pollution density and polymer functional groups [88]. Additionally, particle size, shape and particle-polymer bond potential are the utmost significant features of inorganic fillers to improve the polymer characteristics (electrical, mechanical and thermal) [142].

Neat SiR exhibit poor dielectric, thermal and mechanical performance, which hinders its use as the HV flexible insulants [20]. The authors of [143], have investigated the impact of particle size, its surface modification and tracking resistances. In other works, the authors [144] studied the influence of thermal conductivity on dc resistance to erosion of $\mathrm{SiR} / \mathrm{BN}$ nano-composites. They inferred that with the increase in particle concentration from 0 to $7 \mathrm{wt} . \%$, thermal conductivity enhances, thereby reducing the weight loss and erosion. Likewise, the authors of [145] have examined the effect of barium titanate $\left(\mathrm{BaTiO}_{3}\right)$ on surface degradation and tracking resistance of room temperature vulcanized (RTV)-SiR composites.

Sim et al. [146], studied the effect of $\mathrm{ZnO}$ and $\mathrm{Al}_{2} \mathrm{O}_{3}$ particles on thermal-expansion-coefficient and thermal conductivity of SiR composites. They concluded that the thermal-conductivity of thermal-pads increases with increasing $\mathrm{ZnO} / \mathrm{Al}_{2} \mathrm{O}_{3}$ particles. The authors of [147] investigated the impact of Divinylhexa [(trimethoxysilyl)ethyl]-POSS (DVPS) on SiR's mechanical and thermal degradation, and thermooxidative stability characteristics using tensile testing and thermo-gravimetric analysis. They found significant increase in mechanical and thermal stabilities.

Some scholars presume that SiR-composites deterioration process may be explained and described by optical/thermal-oxidative reaction-mechanism, which leads to SiR side-groups (organic chains) oxidation [148]. Consequently, this thermal- degradation leads to cracking, hardening and colorfading of SiR surface. In other work, Li Yaozhong et al. [149] investigated organic-groups variation and thermal-analysis of HTV-SiR using differential-scanning calorimetry (DSC) and thermal-gravimetric analysis (TGA). They inferred that both TGA and DSC are good analysis methods to study the SiR thermal stability and chemical changes.

Furthermore, the authors of [150] noticed that thermal-decomposition temperature of epoxy-claynano composites were higher than neat-epoxy matrix. Likewise, for epoxy-clay-nano composites, the significant improvement in thermal stability was attained with reactive-phosphorous by activation energy estimation [151]. According to the authors of [152], the amalgamation of unmodified-clay with epoxy-resin does not yield significant change in decomposition temperature, whereas the organicallymodified-clay ( $3 \mathrm{wt} . \%$ ) increases the thermal-decomposition-temperature by about $15^{\circ} \mathrm{C}$. In addition, the authors of [153], verified from TGA analysis that nano-composites exhibited higher thermalstabilities compared to neat RTV-SiR.

The enhancement in thermal-stability was affirmed by incorporation of nano-alumina and nanosilica into polyamide matrix $[154,155]$. El-Hag et al. [156], inferred from TGA results that compared to nano-silica (without-homogenous-dispersion), the micro-silica (with-homogenous-dispersion) exhibited higher thermal stability.

\subsubsection{Electrical characteristics}

For $\mathrm{HV}$ insulations, the most challenging job of an engineer is to select the proper material with optimum electrical properties at the lowest cost. To characterize the condition of polymeric materials for particular applications, a number of assessable parameters such as Permittivity (å) and capacitance (C), resistivity (volume \& surface), dielectric strength, time constant, dielectric dissipation factor and partial discharge can be employed $[157,158]$.

a. Relative-permittivity $\left(\varepsilon_{\mathrm{r}}\right)$ and Capacitance (C) Relative-permittivity can be defined as the capacitance ratio of identical-electrode systems using dielectric material, compared with similar electrode using vacuum as a dielectric. Mathematically, it is given by the following formula:

$$
C=K \varepsilon_{r} \varepsilon_{0},
$$

where $k$ represents the system geometrical structure and $\varepsilon_{\mathrm{o}}=8.85410^{-12} \mathrm{~F} / \mathrm{m}$ is the vacuum permittivity. The permittivity values vary from 1 to 5.5 for air and porcelain, respectively. In addition, for cap- 
and-pin-type insulators and power capacitors, the capacitance varies from few $\mathrm{pF}\left(10^{-12}\right.$ farads) to $\mu \mathrm{F}$ $\left(10^{-6}\right.$ farads, respectively. For power system applications, little variation in permittivity takes place even at higher frequencies and stresses. However, their measured values may be affected by trapped-gas or moisture.

b. Insulation Resistance (IR) and Resistivity ( $\rho$ ) Resistivity and insulation resistance are very important electrical properties to evaluate the performance of polymer-insulants. It can be further categorized as volume and surface resistivitys.

c. Volume Resistivity $(\Omega-\mathrm{m})$ : It is the resistance offered by dielectrics between opposite-faces of a 1 $\mathrm{m}^{3}$ (1-cubic-meter). So the insulation-resistance can be calculated by the following relation:

$$
R=\frac{\rho L}{A}(\Omega),
$$

where $A$ represent cross-sectional area, $L$ is the length (spacing) between electrodes and $\rho$ represents material resistivity.

d. Surface Resistivity ( $\Omega-\mathrm{m})$ : It is a very important parameter to assess the surface state of any material. It can be defined as the resistance offered by a unit-square of insulants between two-opposite sides. Considerable variation in surface resistivity can occur with temperature, acid-rain, fog, UV-radiations, which will eventually decrease the insulation-resistance over aging. Moreover, in the design of multiple-dielectrics, the relative-values of both resistivities (volume \& surface) are very important.

\section{e. Time-constants}

Time-constant is another important parameter to quantify the quality of insulation system. It can be calculated by applying the direct-voltage-pulse to the sample under test and measuring the rise-time up to peak value followed by predefined discharging time and measure the recovery-voltage. Moreover, the frequency-response and complex-impedance of the equivalent resistive and capacitive networks have significant impact on time-constant property. Additionally, variations in time-constant become prominent while measuring resistivity and resistance of insulants.

\section{f. Dielectric-dissipation-factor}

In a dissipative system, the dielectric-dissipationfactor (DDF) or loss-tangent is a measure of energyloss-rate of electrical, mechanical or electromechanical system. Quality factor is the reciprocal of DDF. However, in operating conditions of dielectrics, finite-losses may occur due to leakage-current conduction. These losses are indicated by slight-change

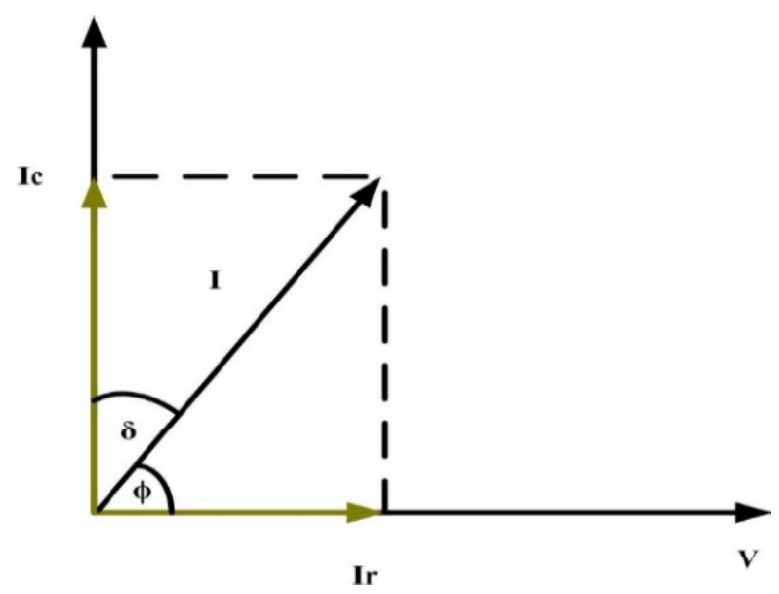

Fig. 10. Practical-dielectric (lossy) phasor-diagram.

in current phase with-respect to the applied AC-voltage as described in Fig. 10. Mathematically powerfactor and DDF is given by the following relations:

$$
\begin{aligned}
& P F=F\left(I_{r} / I\right)=\cos (\varphi), \\
& D D F(\tan \delta)=I_{r} / I_{c} .
\end{aligned}
$$

The angle ' $\varphi$ ' here indicates power-factor angle, whereas angle ' $\delta$ ' represents loss-angle. The current component ' $l_{r}$ ' indicate losses and ' $l_{c}$ ' represent the charging current. For good-insulation, the loss-tangent should be minimum, which varies from dielectric to dielectric.

\section{g. Partial-Discharges (PDs)}

The localized electrical-discharge that only bridges the isolation (insulation) system among conductors, which may or may not occur with adjacent-conductors. According to the IEC-60270 standard, which states that on insulant surface or in the insulation, PDs commonly occurs due to strong electrical stress (greater than dielectric strength) of less than 1 is. Moreover, it is noted that light, heat, sound and chemical-reactions are often executed by PDs. At the terminals of dielectric materials, PDs manifest themselves a pulses of very small duration (ns- $\mu s$ ) and amplitudes ( $\mu \mathrm{V}$ to $\mathrm{V}$ ). Furthermore, in all types of polymeric materials PDs may occur in any one form, i.e. surface-discharge, internal-discharge, treeing and corona. The literature review related to various electrical properties and micro/nano-sized fillers performance in polymer-insulants are summarized in the following paragraph.

In literature, the influence of nano-particles on dielectric-strength has been broadly cited $[91,159]$. The authors of [160] investigated that composites filled with smaller-size particles exhibit higher resistance to PD compared to fillers of larger size. 


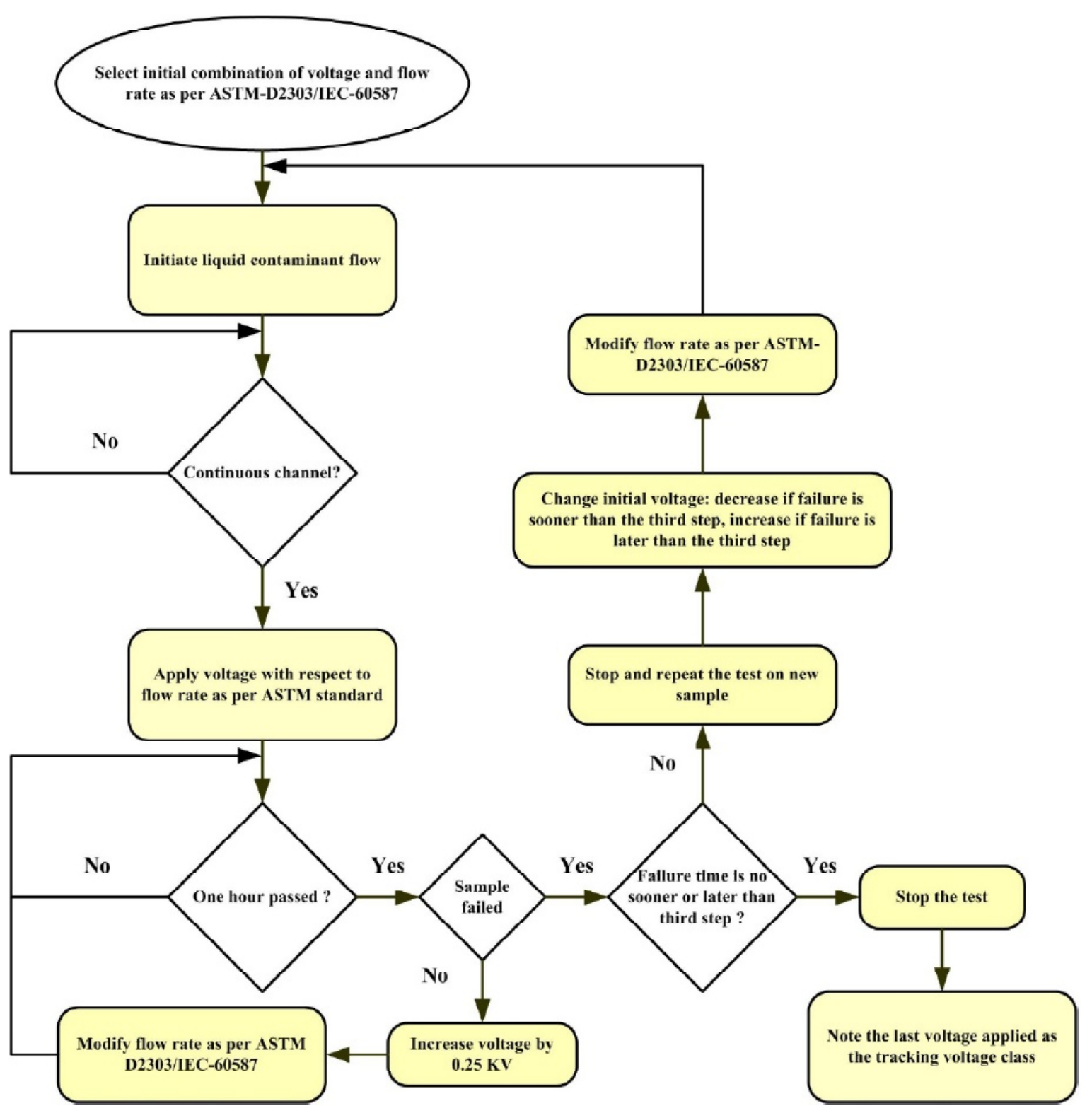

Fig. 11. Inclined-plane-test stepwise flowchart.

Masood et al. [161] found that in the medium of liquid-nitrogen, volume resistivity, surface resistivity and DDF has been correlated with the dielectricbreakdown strength of solid dielectrics.

In other study, Tariq et al.[162] analyzed the impact of AC-corona discharge on SiR composites with nano-silica. They found that SiR-blends filled with nano- $\mathrm{SiO}_{2}$ at $5 \mathrm{w} . \%$ exhibit higher resistance to corona compared to neat and other composites.

Likewise, the authors of [163], concluded that RTV-SiR exhibit higher corona-resistance compared to HTV-SiR. In another study, Alapati et al. [164] inferred that incorporation of nano-alumina into epoxy matrix reduces the electrical-tree inception. Furthermore, the authors of [165] investigated the influence of polyhedral oligomeirc-silsesquioxanes (POSS) particles on the erosion-resistance, partial discharge, dielectric response and breakdown-strength of epoxy composites. They concluded the correlation among particle structure and characteristics of epoxy/POSS composites.

In addition, for many applications like electric cars and compensation systems, the capacitors with higher power and energy density are required. The capacitor energy-density is dependent on dielectric medium permittivity. Hence, to achieve higher energy-density, capacitors and insulants of enhanced resisitvities, high-permittivity micro/nano particles (i.e., barium-titanate) are frequently amalgamated with polymer matrix [166-168].

From literature survey, it is obvious that the amalgamation of suitable micro/nano particles into poly- 
mer matrix can increase the dielectric-strength, PDs resistance, resistivities (volume and surface), voltage-endurance and reduce the accumulation of space charges. For various applications, composites can be compounded by loading of different fillers in different percentages to achieve the desired permittivity. Moreover, for a given formulation, the achievement of desired properties (mechanical, thermal and electrical) depends on filler dispersion, size, type and loading.

\subsubsection{Tracking and erosion resistance}

In the development of HV insulators, estimation of erosion resistance and electrical-tracking of polymer insulants is a fundamental task. "Erosion" means material weight-loss, whereas "tracking" means the surface-carbonaceous path formation. Breakdown due to tracking was a major concern during the early use of organic-insulants. To estimate the erosion/ tracking-resistance of polymer dielectrics, standard screening methods were proposed. Using the standard procedures for tracking/erosion-tests, only relative ranking of polymeric-composites can be achieved, whereas up till now, its absolute measurement is not possible [169].

In literature, various techniques have been proposed to evaluate erosion/tracking resistance of polymeric materials. Among these methods, the comparative-tracking index test and dry-arc-resistance test have limitations due to low voltage applications [170,171]. Mathes et al. [172] proposed the inclined-plane-liquid contaminant test (IPT) for insulants surface tracking/erosion evaluation, which was standardized as ASTM-D-2303 [173,174]. The significance of IPT is reliability, precise control of contamination source, and a wide voltage-range $(>6 . \mathrm{kV})$. Furthermore, to determine the insulant class, the stepwise details of IPT is summarized in Fig. $11[169,173]$.

Recently numerous researchers have studied erosion and tracking resistance of polymer composites. In order to improve tracking/erosion resistance and extend service life of $\mathrm{SiR}$, the micro/nanosized fillers are added in polymer matrix [61]. The degree of material property enhancement depends on, filler type, structure, size, concentration, orientation and dispersion in polymer matrix [11]. Moreover, Venkatesulu et al. [128] investigated the impact of alumina on SiR composites. The authors of [175], demonstrated the effect of micro/nano-fillers on arcing behavior of high temperature vulcanized (HTV) silicone rubber. To evaluate the Dry-Band-Arc- ing (DBA) and tracking/erosion mechanism of HV insulants, various standardized test techniques, like Inclined Plane test (IPT), Dust-and-Fog (DF) test and rotating wheel dip (RWD) tests can be applied [176-178].

Furthermore, during salt-fog test, the influence of the residue relative to the stable DBA development was highlighted [179]. Sarathi et al. [180] investigated the DBA period through wavelet transform. Likewise, the authors of [181] analyzed the DBA leakage current under direct current (DC) statistics. El-Hag et al. [156] noticed the enhancement in tracking/erosion resistance of SiR composites at lower wt.\% of silica particles. Likewise, the authors of [145] studied the amalgamation effect of bariumtitanate on tracking and surface degradation of RTVSiR composites. It has been observed, that bariumtitanate filled SiR blends showed enhanced erosion and surface degradation resistance.

In other work, loganathan et al. [10] studied the influence of nano-silica on tracking/erosion resistance performance of silicone rubber. They found increase in erosion/tracking resistance for both aged and neat composites. Many authors have investigated the influence of various particles on erosion/ tracking resistance and erosion aging of silicone rubber insulants for HV applications [182-185]. However, little research has been done to quantify the combined effect of $\mathrm{ATH} / \mathrm{SiO}_{2}$ particles in different compositions on tracking/erosion resistance of RTVSiR composites for HV insulation applications.

\subsubsection{Water immersion/penetration resistance}

Compared with glass and porcelain insulators, polymer composite insulators are widely used for HV insulations [186,187]. Moreover, in polymer composites, various types of operating issues are still a challenge, which causes a severe breakdown in power system. Besides, electrical and environmental stresses, the aqueous-solutions, moisture and water permeation/penetration plays a significant role in degradation of weather sheds and outer sheath of polymeric insulators [188,189]. Due to partial-pressure difference among environmental conditions and dielectric material, these factors (water/moisture and aqueous solutions) can diffuse into insulator sheds. Consequently, they degrade both mechanical and electrical characteristics of SiR dielectrics through siloxane-chains hydrolysis and increase in loss-tangent [190, 191]. Y. Geo et al. [192] investigated the impact of solution concentration and solution type on HTV-SiR with different ATH contents. They found 
that at higher temperature, the SiR with lower ATH percentage absorbed less liquids compared to higher ATH contents.

Wang et al. [193] reported the influence of aluminum-hydroxide and fumed-silica on permeation and absorption properties of HTV-SiR. They concluded, that the material's internal free-volume has significant role in liquids absorption. Furthermore, it is investigated that water, moisture and fluids can penetrate into weather-sheds and sheath, thereby causing fillers decomposition, interface breakdown between polymer matrix and micro/nanoparticles, increase in leakage current and decrease in dielectric strength $[184,194]$. Hashiguchi et al. [195] studied the impact of ATH on diffusion of water into SiR.

In addition, Ali et al. [196] investigated the correlation among silicone rubber sample weight (immersed in water) with temperature and particles loading. In other work, Manjang et al. [197] studied the effect of water diffusion on waste-coal-fly-ash filled $\mathrm{SiR}$ dielectric characteristics. They reported that water-penetration has significant effect on rubber hydrophobicity and relative-permittivity. The authors of [198], validated the Fick's-2 ${ }^{\text {nd }}-$ law by diffusion of $\mathrm{NaCl}, \mathrm{H}_{2} \mathrm{O}$ and $\mathrm{HNO}_{3}$ solution into HTV-SiR. Other work conducted by [199], suggests that moisture diffusion into polymer rubber follows Langmuirmodel.

However, no research has been conducted that took place the combined effect of $\mathrm{ATH} / \mathrm{SiO}_{2}$ particles on water immersion/penetration-resistance of silicone rubber. Therefore, it is substantial to comprehend the permeation and absorption of deionizedwater into RTV silicone rubber composites.

\section{OVERVIEW OF HIGH VOLTAGE ELECTRICAL INSULATORS}

For operating efficiency and operational-safety of high voltage transmission-lines and substations, electrical insulators are widely used by meeting the system reliability. The main tasks of insulators are to insulate the power line conductor from grounding supports/structures and provide protection to the power system equipment. More than 100-years ago, insulators made of glass/porcelain materials were used for HV distribution and transmission lines $[71,200]$. Although efficiency and reliability of porcelain/ceramic insulators are well known, but heavy weight and maintenance issues limit its applications.

For HV use, a new polymeric insulants (ethylene-propylene rubber (EPR), cycloaliphatic-epoxy (CE)) were developed in the early-1970s, by poly- meric-material industry. Nowadays, polymeric-insulators made of SiR, EPDM and EPR are in extensive use around the world at all voltage levels $[201,202]$. Depending on their functionality, different types of line insulators are employed on transmission and distribution lines, which are classified according to their materials and applications as depicted in Fig. 12 [203].

In addition, for $\mathrm{HV}$ applications, these insulators are exposed to electrical and non-electrical (sunlight, wind, contamination and precipitation) stresses. To ensure the efficiency and safe operation of transmission and distribution lines, HV-insulators must be resistive to erosion/tracking, flammability, arcing, weathering, chemical-attacks, UVradiations, moisture and physical degradations [204]. Additionally, due to enhanced hydrophobicity, higher volume/surface resistivity, low dielectric loss and good tear-strength, the insulators suppresses partial discharges as well as leakage current under densely-contaminated conditions [205]. Different types of HV insulators are discussed in the following section.

\subsection{Porcelain-insulators}

Basically porcelain is the compound of potassiumaluminum-silicate $\left(4 \mathrm{~K}_{2} \mathrm{O} . \mathrm{Al}_{2} \mathrm{O}_{3}\right.$. $\left.3 \mathrm{SiO}_{2}\right)$, which was developed by agglomeration of quartz, clays and potassium-alumino-silicate. For HV applications, porcelain-insulators are still in use as it was introduced in 1850's. Ceramic/porcelain insulators are also used in micro-electronics devices and power equipment. To meet the requirements of HV and modern power-transmission, the manufacturing and design of HV insulators should be enhanced to satisfy the required electrical-leakage-distance. Furthermore, above $100 \mathrm{kV}$, it leads to abnormal results due to massive and longer size [206].

In porcelain insulants, the ratio of amorphous and crystalline phases considerably effects the physical and dielectric characteristics. Characteristically, the insulators made of porcelain are dense, noncombustible and hard. Additionally, its compressive strength is 8-10 times higher than tensile-strength showing enhanced performance. Due to low impact-strength, porcelain insulators tends to fracture, when struck by hard object. It can be further classified into the following three types [202, 207]:

a. Pin-type porcelain-insulator: For rigid mounting usually pin-type insulators are used below 69 kV. Possible puncturing caused by heavy-arcing and mechanical shocks limits its application for higher 


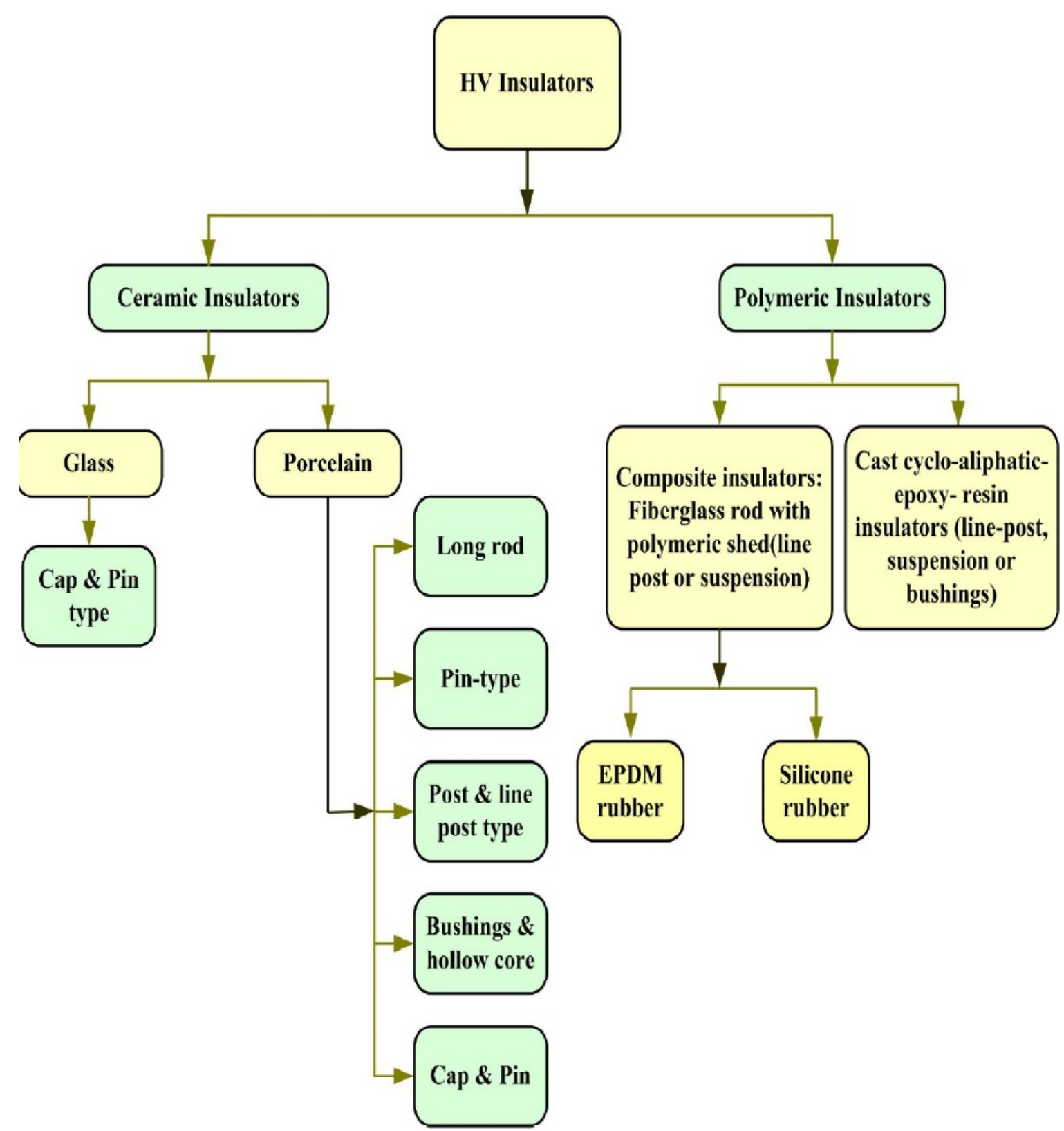

Fig. 12. Classification of $\mathrm{HV}$ insulators.

(more than $69 \mathrm{kV}$ ) voltages. Pin-type porcelain insulator is shown in Fig. 13a.

b. Post-type porcelain-insulator: This type of insulators are used for rigid and direct mounting in the form of columnar shape (Fig. 13b). On the pole sides such insulators can be installed in cross-arms as well as side-post with particular foundations in vertical-configurations.

c. Suspension-type porcelain-insulator: It consist of non-rigid individual-disc insulators which are coupled to each other and consist of coupling and shell-hardware, and cap-and-pin units as shown in Fig. 13c.

\subsection{Glass-insulators}

At the start of $20^{\text {th }}$ century, glass-insulators were proposed for transmission and telegraph lines. With the developments in power transmission, glass was gradually used for high voltage applications. Moreover, due to surface stiffness and Microscopic-cracks glass insulators are breakable thereby leading to weak insulants $[203,208]$. Technically, glass is a high viscous amorphous-liquid, consisting of $75 \%$ silica, 20\% soda-ash and $5 \%$ lime, which is amalgamated with lead, calcium, lithium and cerium oxides. At high temperature, glass is relatively lossy, but at low temperature it can be used as a HV 


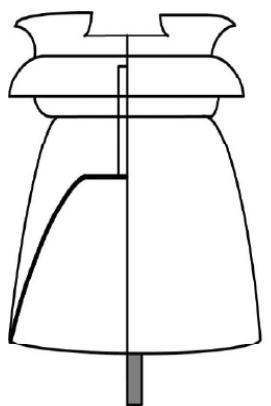

(a)

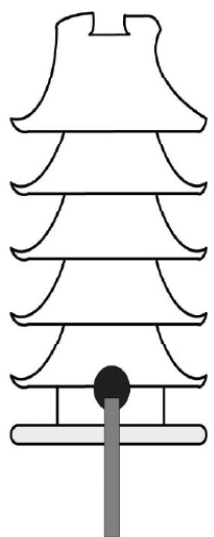

(b)

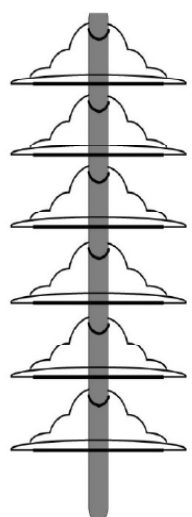

(c)

Fig. 13. A: Pin-type-insulator, B: Post-type-insulator, C: Suspension-type-insulator (Redrawn and adapted figure from [190]).

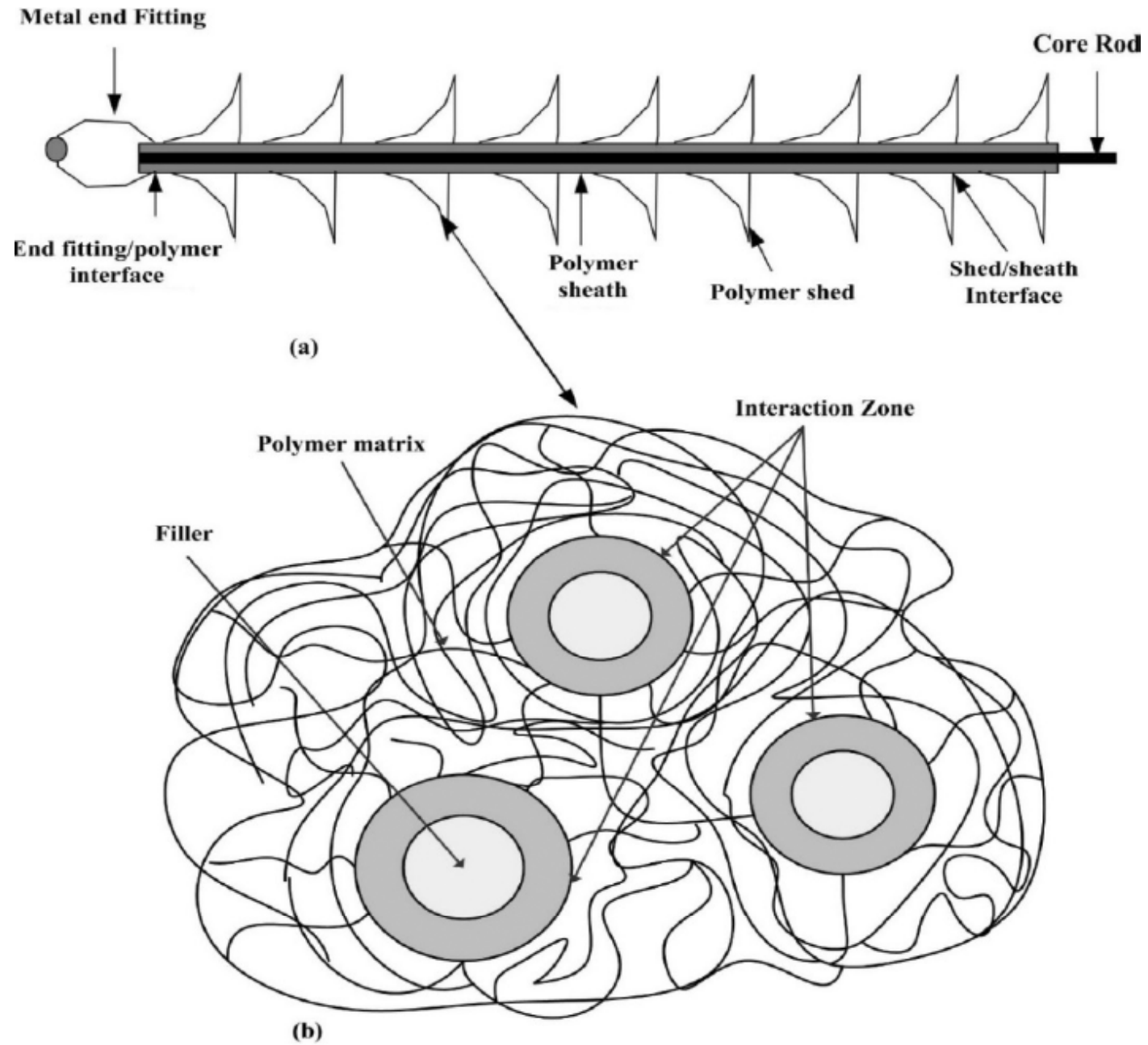

Fig. 14. (a) Composite insulator profile, (b) Weathershed material composition.

insulants. Furthermore, glass-insulators are also found both in disk and pin-type [202].

In addition, for glass-insulators, three defects, i.e., cords, stones and seeds are reported. Cords represents amorphous portion, stones indicate small crystals, whereas seeds are small gaseous bub- bles in glass material. In design, glass insulators are similar to those of porcelain, which possesses higher resistance to dry-band-arcing and flashover voltages. Furthermore, these materials are wet-able (in wet-conditions) due to higher surface-energy. Consequently, leakage current flows and thereby 

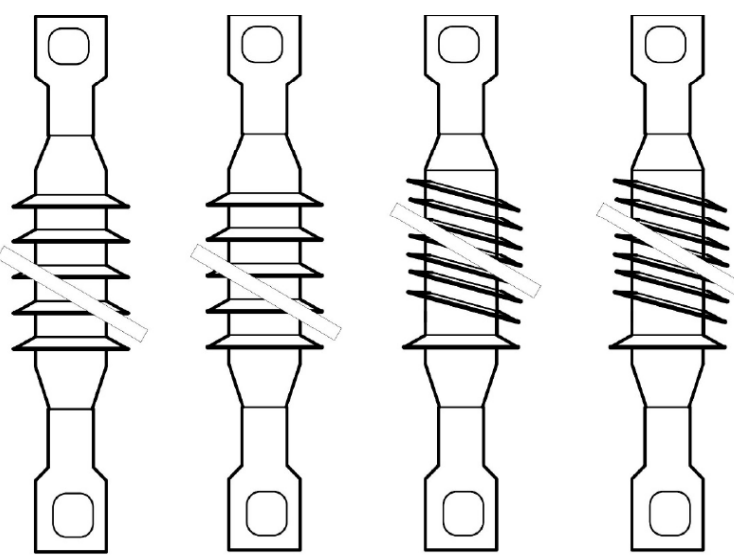

Fig. 15. Polymer-composite insulators: Long-rodtype (Redrawn and adapted figure from [190]).

leads to power system outages and flashover problems. Flashover is still a challenge to overcome in HV transmission lines [209,210].

\subsection{Polymer composite insulators}

The insulator formed by combination of two or more materials (base material + other material) is known as composite insulator. It consist of central core to provide mechanical-strength, weather-sheds for long-time electrical insulation stability and metal end-fittings. The polymer composite insulator profile and weathershed/sheath material constituents are shown in Fig. 14.

Recently, polymer-composite-insulators have captured a wider market share, due to their light weight, easy transportation/ maintenance, better volume/surface resistivity, excellent hydrophobicity and lower cost $[211,212]$. Among polymeric materials, silicone rubber is extensively employed in HV insulations. In HV applications, SiR insulators are simultaneously subjected to environmental, electrical and mechanical stresses, which causes material degradation and surface tracking/erosion $[213,214]$. The progressive degradation of a solid insulating surface due to surface contamination and local discharges, result in the formation of conducting path, which is known as tracking. Therefore, a quantified and considerable understanding of resistance to tracking/erosion during service condition of $\mathrm{SiR}$ is needed [44,215].

Worldwide, a considerable effort has been devoted to enhance the performance and reliability of polymer insulants by improving the erosion/tracking resistance. However, tracking is still the main common degradation problem to be overcome in SiR HV insulations.

Furthermore, polymeric composite insulators are fabricated either as post or long-rod type as shown in Fig. 15. Nowadays, polymer-composite insulants are widely used for bushings of instrument-transformer, surge-arresters housing as well as line terminations. Additionally, for polymer-composites, the mostly used materials are RTV/HTV-SiR, EPR, and EPDM for high voltage insulations [92,202]. The fiberreinforced core and sheath/shed interfaces of composite-insulators are sensitive to liquids/moisture permeation. Therefore, it is required that polymer housing should withstand the environmental and electrical stresses without losing electrical, mechanical and thermal characteristics [216-218].

For HV transmission-lines, substations and electrical apparatus, the use of polymer-composite insulators have been successfully achieved. It is now conceivable to plan the whole substation based on composite-technology. Furthermore, based on damage-risk-minimization and operational safety, majority of bushings are fabricated using compositetechnology. Composite insulators can be further classified on the basis of applications as follows [71]:

- Composite-long-rod insulators

- Composite post-insulators

- Insulated-cross arms for compact lines

- Interphase spacers

- Composite hollow-core insulators

Furthermore, oxidative stability, weathering resistance, chemical inertness and temperature insensitive physical properties are important characteristics of polymer composites, which are correlated with its molecular structure. The coating of $\mathrm{SiR}$ on ceramic insulants is an effective technique to enhance the insulator performance (mechanical, thermal and electrical), which has been investigated by many authors and are effectively employed as maintenance tool (by power utilities) $[103,219,220]$.

Despite of many advantages, they (polymercomposite insulators) are susceptible to chalking, surface erosion/tracking, sheds hardening, discharges, brittle and bonding fracture, electrical failure and increased-contamination. These limitations of composite insulators have forced the researchers and manufacturers to develop the composite insulators with satisfactory performance at all voltages and contaminated environmental conditions [203,221].

\section{AGING OF POLYMER COMPOSITE INSULATORS}

For HV insulations, the polymer-composite insulators have been used around the world for more than 50 years. Polymer composite insulators, with glass fiber core, metal end fitting and silicone rubber outer 


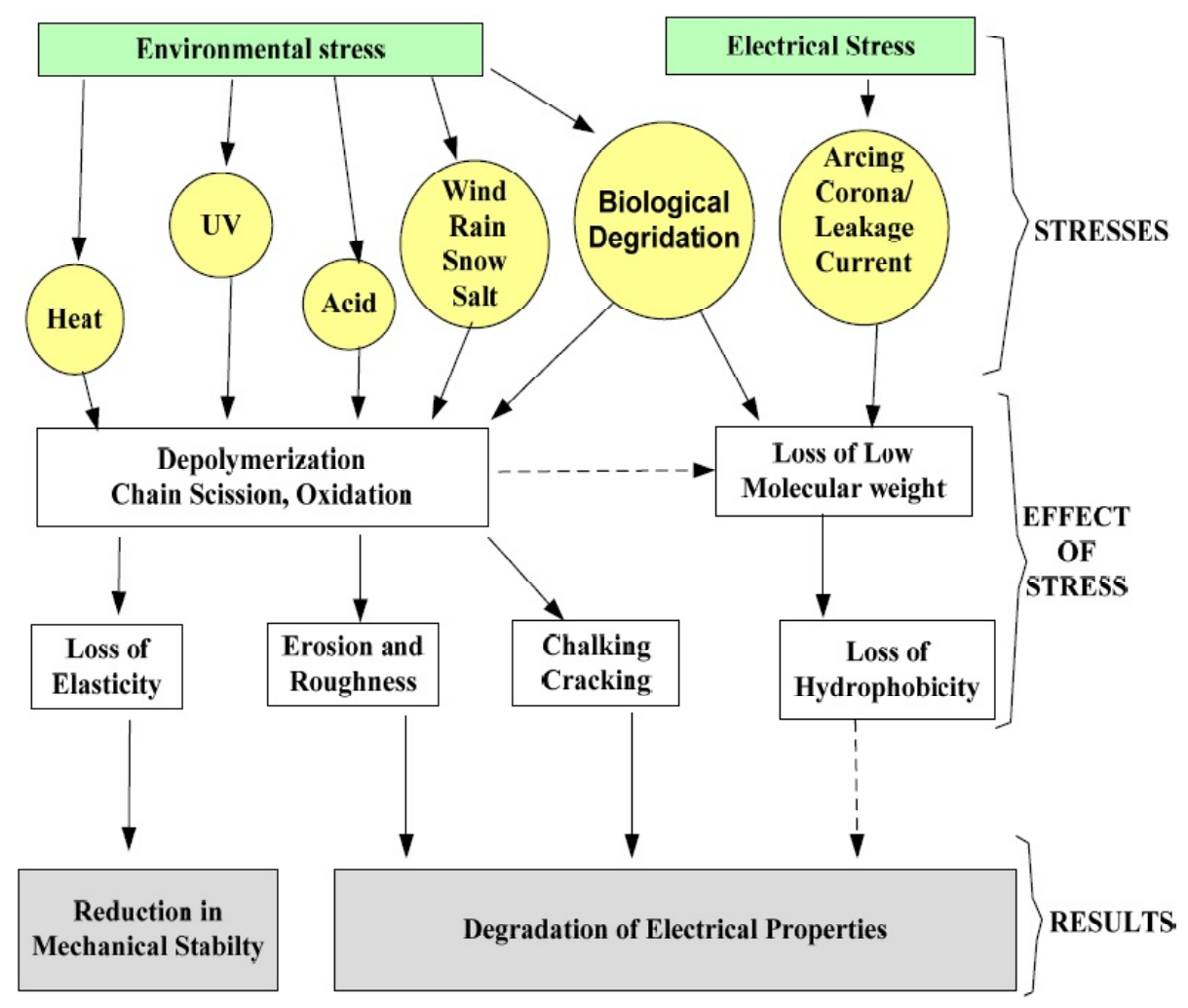

Fig. 16. Factors involved in aging of a polymeric insulator.

sheds/sheath are promising, reliable and emerging candidates for high voltage transmission and distribution systems [19]. Moreover, silicone rubber insulants with excellent electrical, mechanical, chemical, anti-pollution and superior aging performance are increasingly replacing the porcelain and glass insulators [222]. However, due to mechanical, electrical and environmental stresses (UV radiation, dry-band arcing), polymer insulants in service condition become hydrophilic and allow leakage current (LC) to flow through the surface. Consequently, surface tracking, erosion, hydrophobicity loss, partial discharge and complete failure takes place [223]. Moreover, the main hindrance of polymer composite insulators are the long-term performance and un-known aging behavior in different environmental conditions [224].

These irreversible and long-term changes in physical-properties of polymer-insulator due to the influence of one or more stresses are known as aging [9]. The deterioration caused by one factor is known as single factor aging, whereas deterioration caused by many factors is called multi-factor aging. Furthermore, over the course of weathering, the degradation due to aging may become so effective that complete breakdown of insulation occurs [225].

Primarily, aging influences the insulation service life, beyond which the insulant would not be able to work properly. For instance, if the electric field (stress) is increased beyond the insulant dielectricstrength, the insulator would fail (breakdown). It means that with increase in stress magnitude and time, the insulation failure-rate increases [226]. Hence, the characteristics (mechanical, thermal and electrical properties) of an insulators which are affected by aging, relies the stress nature as well as type of polymeric material. Stresses which produce aging are called aging factors. The important stresses and their effects on insulator characteristics are summarized in Fig. 16 [225,227].

In addition, with the passage of time, aging of polymer insulants become so serious that dielectric-breakdown finally occurs. In this case, insulation life can be determined by knowing the final breakdown time. Practically, measuring the failure time is tedious and time consuming, because mostly it takes decades to breakdown. However, to predict the insulation life and time to breakdown, the actual field environment can be simulated in multistressaccelerated aging chamber according to ASTM/IEC standards [34,228 229].

In addition, each year, photo-degradation and weathering of polymer insulants causes millions of dollars of valuable equipment damage, which includes strength loss, color changes, chalking, arcing, tracking and erosion [230]. Due to inorganic nature they (SiR insulators) are more susceptible to chemical changes and weathering, thereby re- 

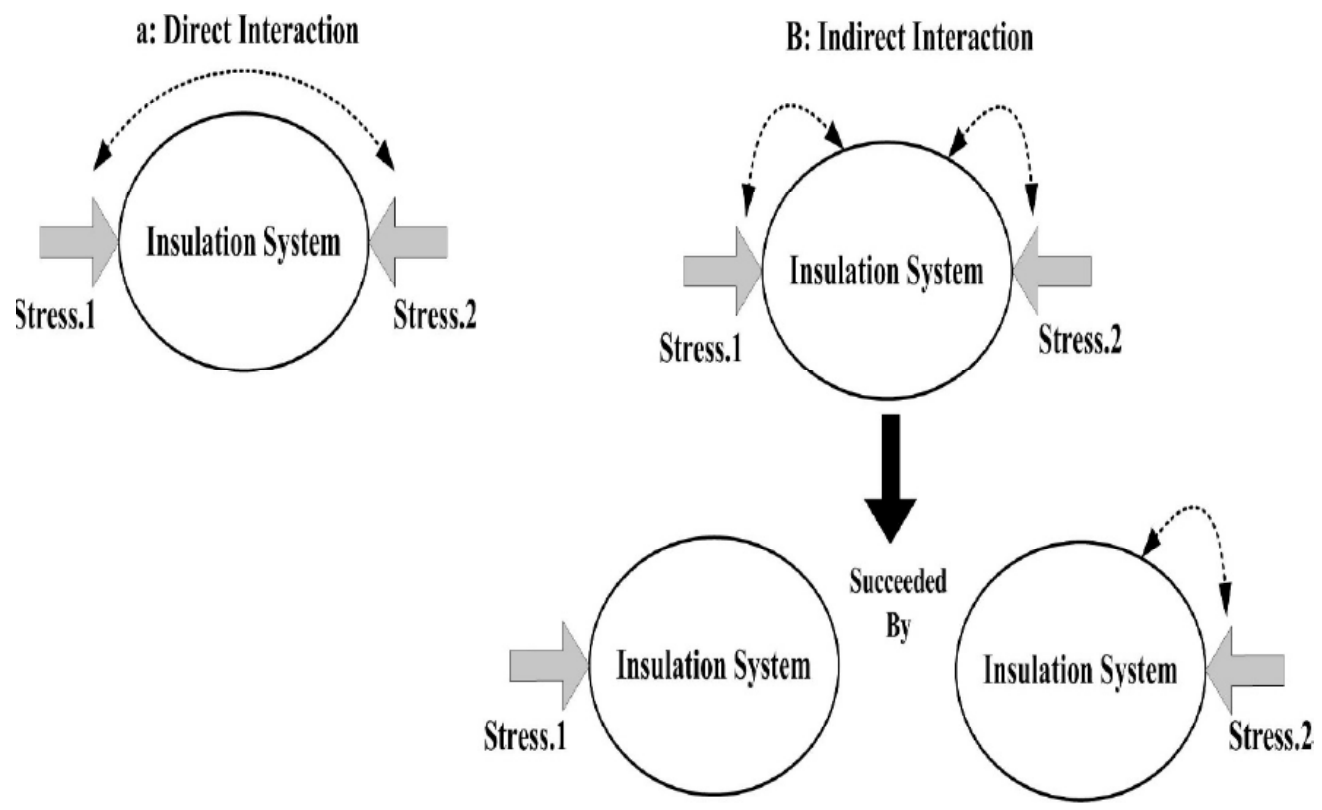

Fig. 17. (a) Direct Interaction, (b) Indirect Interaction.

ducing their long-term performance and reliability [231].

Over the past decade, many scholars, have investigated the impact of environmental, electrical, mechanical and thermal stresses on performance of composite insulators. The authors of [232,233] reported the benefits of ATH and silica in SiR formulations. Likewise, the authors of [234], investigated that insulators failure is initiated by dry-band arcing and large leakage current. Other researchers investigated the correlation among discharge activity, leakage current, aging deterioration and surface wettability of insulator $[28,42,235]$. Furthermore, the authors of [236], studied the lab and field aging of $28 \mathrm{kV}$ polymeric insulators in US environment under the influence of various stresses.

Moreover, many researchers have investigated the effects of thermal, UV-radiation, tracking and corona discharge on aging and characterization of insulator sheds [6,28,83,145,146,237-239]. To simulate the actual service condition of composite insulants, various types of accelerated-weathering (aging) experiments were conducted under the influence of multiple or single aging factors. However, the insulator service condition in different areas/countries varies, therefore no monotonous and mature test technique is available [41].

Gorur et al. [43] indicated that in HV serviceconditions the aging of polymer-insulators begins with the hydrophobicity-loss due to DBA and weathering. Chen et al. [148], examined higher degradation of organic-groups on the side-chains than the backbone (Si-O-Si) of liquid-silicone-rubber. In an- other study, Nazir et al. [162] studied the effect of AC-corona discharge on SiR aging at higher altitudes. They indicated that by dispersion of nanosilica (5 wt \%) in base-matrix (SiR), corona-resistance can be improved.

Moreover, the authors of [240], reported that the fuzzy-comprehensive-evaluation-model can reflect the insulators aging-state accurately. Du et al. [241] investigated the influence of Silicon carbide (SiC) particles on space-charge behaviors of HTV-SiR composites. They suggested that under high electric field, the dc-conductivity of $\mathrm{SiR} / \mathrm{SiC}$-composites can be improved.

In other work Cheng et al. [242] studied the correlation among the operating years and aging-index. They determined that the lifespan of SiR insulants can be predicted by knowing their thermal oxidation process. Moreover, polymer insulants operating life in service-conditions can be predicted by using corresponding aging models [225,226,243]. The most suitable approach to improve the time-tofailure of polymer-insulators is knowing the physics and chemistry of aging-process [244].

\subsection{Synergy concepts}

Under the influence of electrical and thermal (elevated-temperature) stresses, the failure of polymeric materials may occur sooner compared to the individual stresses. In this case the insulation failure may not be due to the combined stresses (thermal and electrical-aging), but another phenomenon known as synergy effect takes place under the influence of several stresses. The interaction among 


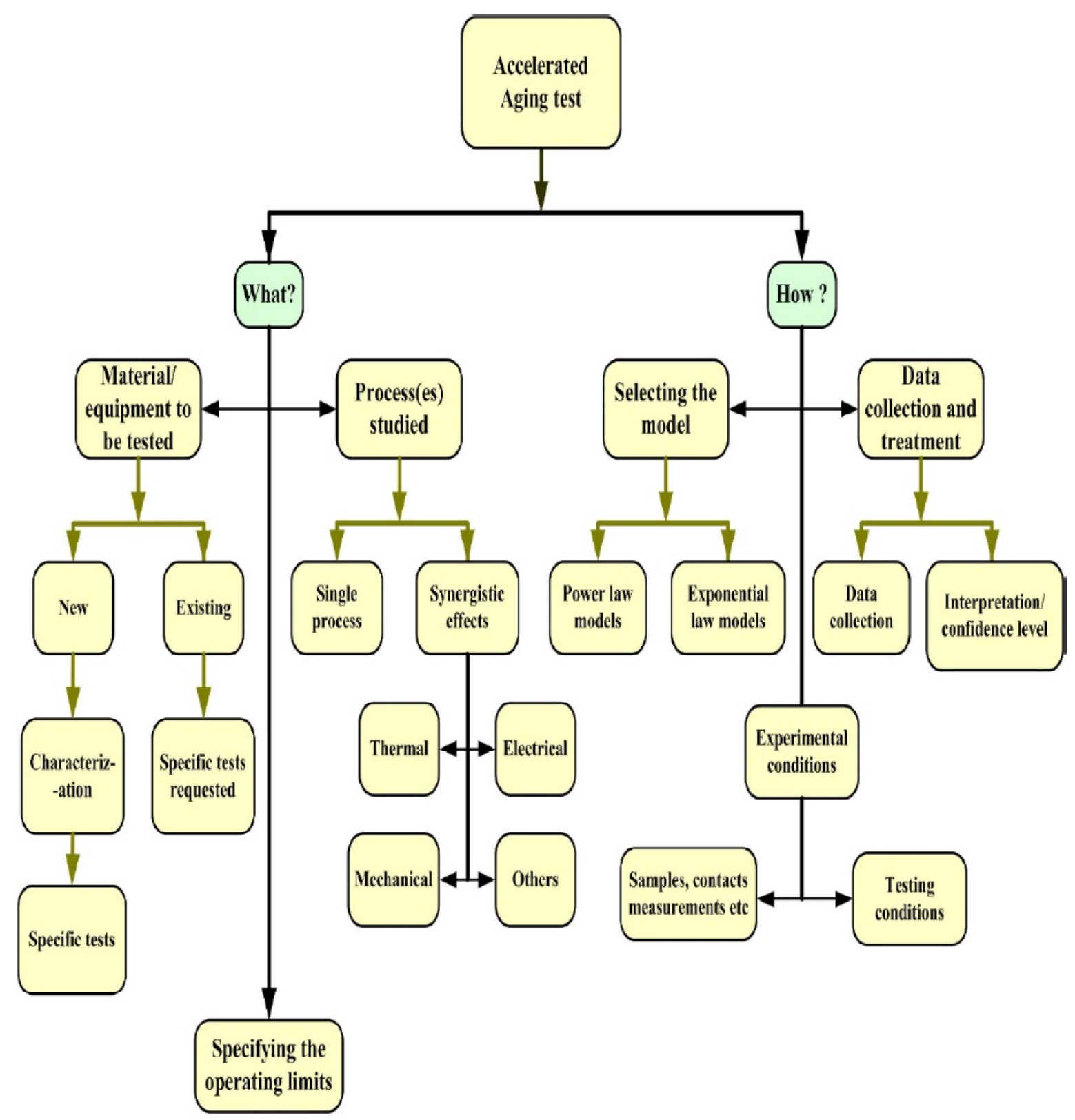

Fig. 18. Different steps of accelerated-aging-tests.

different aging-stresses (factors) are known as synergy-effects [225]. It can be classified as directinteraction and indirect-interaction [245].

a. Direct interaction: The interaction among concurrent (simultaneous) applied-stresses (i.e., thermal \& electrical factors), which varies from sequentially applied stresses is known as direct interaction. Fig. 17a, shows that insulation-system is exposed to two stresses instantly instead of sequential stresses. Example of direct-interaction is the oxidation: which require both oxygen and temperature to produce synergy-effect.

b. Indirect interaction: The interaction among concurrent (simultaneous) applied stresses (factors) which remain un-changed with sequentially applied- stresses as summarized in Fig. 17b. This type of interaction is caused by aging-factors (stresses). Subsequently, the insulation-system may be exposed to electrical-stresses (or simultaneously-applied) which leads to additional weathering due to partial-discharges (synergy-effects).

\subsection{Testing of insulation aging}

Over the past years much effort has been done to predict the lifetime of electrical-insulators. Yet, there are few empirical-tests and concepts which describe the in-service aging phenomenon of HV insulation systems. Under normal operating conditions, the life-prediction of polymer insulators are out of the 
question (longer duration testing not possible). Moreover, to quantify and simulate the insulator operating-conditions, it is usual to perform accelerated-weathering-tests by exposing polymer samples to single or multiple-stresses (mechanical, electrical and thermal) according to the standard procedures $[246,247]$.

In addition, planning the multi-stress-accelerated aging-test is not a simple task because it includes a number of parameters, which comprises all inservice degradation. Hence, it is pertinent to define distinct aims and understand the in-service stresses/ factors before conducting accelerated-aging tests. Additionally, before planning process, two important points should be considered as follows:

- Desired test objectives (i.e., what you wish to learn from the test) and

- Test procedure (i.e., how you expect to achieve the test).

In the planning and development of multi-stressaccelerated aging tests, various-steps are summarized in Fig. 18 [248]. Moreover, in the determination of aging-tests, the selection of an appropriateaging model which explains the aging process under consideration is of utmost importance. Furthermore, the model selection measurement techniques and data-analysis methods are also critical.

\section{CONCLUSIONS}

For high voltage insulations research and development of polymer insulants are challenging. In the last decades many researchers have reported the benefits of such emerging polymer insulants. Moreover, many queries remains to be answered. In order to elucidate the fundamental relationship between properties (mechanical, thermal and electrical) and structure of polymer composites, their detailed characterization analysis is needed. In consequent, this relationship will help in understanding the chemistry and physics of micro/nano blends of polymer insulants. Hence, upon knowing all the mechanisms and properties of SiR matrix, the desired composites with tailored properties can be developed for $\mathrm{HV}$ insulations.

\section{REFERENCES}

[1] M. Katz and R. J. Theis // IEEE Electrical Insulation Magazine 4 (1997) 24.

[2] X. Wang, S. Kumagai and N. Yoshimura // IEEE transactions on Dielectrics and Electrical Insulation 5 (1998) 909.
[3] I. Ramirez, E. A. Cherney and S. Jarayam // IEEE Transactions on Dielectrics and Electrical Insulation 19 (2012) 218.

[4] M. K. Moghadam, J. Morshedian, M. Ehsani, M. Bahrami and H. Saddadi // IEEE Transactions on Dielectrics and Electrical Insulation 20 (2013) 711.

[5] R. Sarathi, S. Chandrasekar and N. Yoshimura // IEEE transactions on power delivery 21 (2006) 243.

[6] J. Reynders, I. Jandrell and S. Reynders // IEEE Transactions on Dielectrics and Electrical Insulation 6 (1999) 620.

[7] W. Song, W.-W. Shen, G.-J. Zhang, B.-P. Song, Y. Lang, G.-Q. Su, et al. // IEEE Transactions on Dielectrics and Electrical Insulation 22 (2015) 961.

[8] R. Gorur, A. De La O, H. El-Kishky, M. Chowdhary, H. Mukherjee, R. Sundaram, et al. // IEEE transactions on dielectrics and electrical insulation 4 (1997) 79.

[9] S. Thong-Om, W. Payakcho, J. Grasasom and B. Marungsri // World Academy of Science, Engineering and Technology 80 (2011) 533.

[10] N. Loganathan, C. Muniraj and S. Chandrasekar // IEEE Transactions on Dielectrics and Electrical Insulation 21 (2014) 2172.

[11] L. Meyer, E. Cherney and S. Jayaram // IEEE Electrical Insulation Magazine 20 (2004) 13.

[12] S. Kumagai and N. Yoshimura // IEEE Transactions on dielectrics and electrical insulation 8 (2001) 203.

[13] C. Meichsner, T. Clark, P. Groeppel, B. Winter, B. Butz and E. Spiecker // IEEE Transactions on Dielectrics and Electrical Insulation 19 (2012) 786.

[14] A. Pustak, I. Pucić, M. Denac, I. Švab, J. Pohleven and V. Musil // Journal of applied polymer science 128 (2013) 3099.

[15] G. Wypych, Handbook of Fillers (2nd ed. Toronto: ChemTec Publishing, 1999).

[16] C. Zhao, H. Qin, F. Gong, M. Feng, S. Zhang and M. Yang // Polymer Degradation and Stability 87 (2005) 183.

[17] J. W. Gilman, C. L. Jackson, A. B. Morgan, R. Harris, E. Manias and E. P. Giannelis // Chemistry of Materials 12 (2000)1866.

[18] M. F. Frechette, M. L. Trudeau, H. D. Alamdar and S. Boily // IEEE Transactions on Dielectrics and Electrical Insulation 11 (2004) 808. 
[19] M. Amin and M. Salman // Rev. Adv. Mater. Sci 13 (2006) 93.

[20] S. Amin and M. Amin, In: Emerging Technologies 2009. ICET 2009. (ICET, 2009), p. 114.

[21] M. Amin, S. Amin and M. Ali //Rev. Adv. Mater. Sci 21 (2009) 75.

[22] M. Amin, A. Khattak and M. Ali // Micro \& Nano Letters 11 (2016) 765.

[23] M. Amin, M. Akbar and S. Amin //Rev. Adv. Mater. Sci 16 (2007)10.

[24] M. Amin, M. Akbar and M. Salman // Science in China Series E: Technological Sciences 50 (2007) 697.

[25] S. Amin //Journal of Elastomers \& Plastics $44(2012) 115$.

[26] S. Amin, M. Amin and R. Sundrarajan, In: Electrical Insulation and Dielectric Phenomena 2008. CEIDP 2008. (CEIDP, 2008), p. 293.

[27] M. Amin, M. Akbar and M. N. Khan // IEEE Electrical Insulation Magazine 23 (2007) 44.

[28] A. k. a. M. amin // Journal of polymer engineering 4 (2015) 11.

[29] M. A. C. Salman Amin, Sheraz Azam // The Nucleus 51 (2014) 418.

[30] M. Ali and M. A. Choudhry // Materials Science-Poland 33 (2015)213.

[31] M. Ali, PhD thesis, Electrical Engineering (U.E.T Taxila, Pakistan, 2014).

[32] A. Khattak and M. Amin // Rev. Adv. Mater. Sci 44 (2016) 194.

[33] A. Khattak, M. lqbal and M. Amin, Science and Engineering of Composite Materials 24 (2017) 679.

[34] A. Khattak and M. Amin // Journal of Polymer Engineering 36 (2016) 199-209.

[35] Y. Fukushima and S. Inagaki //Journal of Inclusion Phenomena 5 (1987)473.

[36] M. Z. Min Zhi Rong, Yong Xiang Zhe and Klaus Friedrich //Polymer 42 (2001)4.

[37] M. A. Douar, A. Beroual and X. Souche // Dielectrics and Electrical Insulation, IEEE Transactions on 22 (2015) 1644.

[38] G. Pan, J. E. Mark and D. W. Schaefer // Journal of Polymer Science Part B: Polymer Physics 41 (2003)3314.

[39] T. F. Baumann, T. V. Jones, T. Wilson, A. P. Saab and R. S. Maxwell //Journal of Polymer Science Part A: Polymer Chemistry 47 (2009)2589.

[40] M. K. Moghadam, J. Morshedian, M. Ehsani, R. M. Laine, K. Lim Yan and N. Umehara //
IEEE Transactions on Dielectrics and Electrical Insulation 21 (2014) 244.

[41] T. Tanaka, "Aging of polymeric and composite insulating materials // IEEE Transactions on dielectrics and electrical insulation 9 (2002)704.

[42] N. Yoshimura, S. Kumagai and S. Nishimura // IEEE Transactions on Dielectrics and Electrical Insulation 6 (1999)632.

[43] R. S. Gorur, G. Karady, A. Jagota, M. Shah and A. M. Yates //IEEE Transactions on Power Delivery 7 (1992) 525.

[44] S. Rowland, Y. Xiong, J. Robertson and S. Hoffmann //IEEE Transactions on Dielectrics and Electrical Insulation 14 (2007) 130.

[45] M. K. Moghadam, J. Morshedian, M. Ehsani, R. M. Laine, L. Y. Kuang and N. Umehara // IEEE Transactions on Dielectrics and Electrical Insulation 21 (2014) 244.

[46] A. Colas // Dow Corning, Life Sciences 2005.

[47] M. A. Roux, Processing pharmaceutical polymers (Smithers Rapra Ltd., 2007).

[48] N. Foster, R. Mammucari, F. Dehghani, A. Barrett, K. Bezanehtak and E. Coen // Industrial \& Engineering Chemistry Research 42 (2003)6476.

[49] Shin Etsu: Characteristic properties of SiR compounds 2003, https://www.shinetsu silicone-global.com/catalog/.

[50] E. Benedetti, C. Pedone and G. Allegra // Macromolecules 3 (1970) 16.

[51] S. J. Clarson, M. J. Owen, S. D. Smith and M. E. Van Dyke, Advances in silicones and silicone-modified materials (ACS Publications, 2010).

[52] M. Sangermano, F. Deorsola, D. Fabiani, G. Montanari and G. Rizza // Journal of applied polymer science 114 (2009)2541.

[53] J. K. Nelson and J. C. Fothergill // Nanotechnology 15 (2004)586.

[54] B. Wood, P. Hodge and J. Semlyen // Polymer 34 (1993)3052.

[55] R. Bischoff and S. Cray //Progress in Polymer Science 24 (1999) 185.

[56] G. Schottner //Chemistry of Materials 13 (2001) 3422.

[57] K. Zong and J. R. Reynolds // The Journal of organic chemistry 66 (2001)6873.

[58] E. Cherney // IEEE Electrical Insulation Magazine 11 (1995)8.

[59] E. Cherney, A. El-Hag, S. Li, R. Gorur, L. Meyer and I. Ramirez // IEEE 
Transactions on Dielectrics and Electrical Insulation 20 (2013)237.

[60] R. Macey, W. L. Vosloo and C. Tourreil, The practical guide to outdoor high voltage insulators (Crown Publications, 2004).

[61] G. Momen and M. Farzaneh // Rev. Adv. Mater. Sci 27 (2011) 1.

[62] E. Al-Ammar and B. Arafa // International Journal of Physical Sciences 7 (2012) 6162.

[63] E. Rochow // Transactions of The Electrochemical Society 90 (1946) 303.

[64] M. Owen //Chimie nouvelle 85 (2004) 27.

[65] Y. Apeloig and A. Stanger // Journal of organometallic chemistry 346 (1988)305.

[66] A. J. Barry //Journal of Applied Physics 17 (1946) 1020.

[67] L. Sommer, E. Pietrusza and F. Whitmore // Journal of the American Chemical Society 68 (1946) 2282.

[68] F. Fearon, In: High performance polymers, ed. by R. Seymour and G. Kirsenbaum (Elsevier, 1986), p. 468.

[69] E. G. Rochow, Silicon and silicones: about stone-age tools, antique pottery, modern ceramics, computers, space materials and how they all got that way (Springer, 1987).

[70] S. L. Bass, J. Hyde and R. McGregor // Journal of the American Ceramic Society 29 (1946)66.

[71] K. O. Papailiou and F. Schmuck, Silicone composite insulators: materials, design, applications (Springer Science \& Business Media, 2012).

[72] G. Soreanu, M. Béland, P. Falletta, K. Edmonson, L. Svoboda and M. Al-Jamal // Canadian Biosystems Engineering 53 (2011)8.1.

[73] R. O. Sauer // Journal of the American Chemical Society 66 (1944)1707.

[74] E. G. Rochow, An introduction chemistry of the silicones (Read Books Ltd, 2013).

[75] C. E. Schildknecht, Polymerization processes vol. 29 (John Wiley \& Sons, 1977).

[76] J. E. Kogel, Industrial minerals \& rocks: commodities, markets and uses (SME 2006).

[77] A. Colas and J. Curtis // An introduction to materials in medicine 2 (2004) 80.

[78] J. Kim, M. K. Chaudhury and M. J. Owen // Journal of Colloid and Interface Science 226 (2000)231.
[79] S. Fang, Z. Jia, H. Gao and Z. Guan, In: 2007 Annual Report-Conference on Electrical Insulation and Dielectric Phenomena (IEEE, 2007), p.300.

[80] H. Deng, E. Cherney and R. Hackam, In: Electrical Insulation and Dielectric Phenomena 1993. Annual Report (IEEE, 1993), p. 598.

[81] S. Benli, U. Yilmazer, F. Pekel and S. Oezkar // Journal of applied polymer science 68 (1998) 1057.

[82] K. Pal, R. Rajasekar, D. J. Kang, Z. X. Zhang, S. K. Pal and C. K. Das // Materials \& Design 31 (2010) 677.

[83] R. A. Ghunem, S. H. Jayaram and E. A. Cherney // IEEE Transactions on Dielectrics and Electrical Insulation 22 (2015)14.

[84] Z. Jun-Wei, D. Zhi-Min, L. Wei-Kang, Z. YanHui and G. Chen // IEEE Transactions on Dielectrics and Electrical Insulation 21 (2014)1989.

[85] I. Yousafa, S. Alib and S. Mirzac, In: 10th International Bhurban Conference on Applied Sciences and Technology (IBCAST, 2013), p. 43.

[86] H. Tan and A. I. Isayev // Journal of applied polymer science 109 (2008)767.

[87] I. Hosier, M. A. Rahman, A. Vaughan, A. Krivda, X. Kornmann and L. Schmidt, // IEEE Transactions on Dielectrics and Electrical Insulation 20 (2013)1808.

[88] S. Ansorge, F. Schmuck and K. O. Papailiou // IEEE Transactions on Dielectrics and Electrical Insulation 22 (2015)979.

[89] C. Roland // Rubber Chemistry and Technology 89 (2016)32.

[90] J. Y. Yi and G. M. Choi //Journal of electroceramics 3 (1999)361.

[91] S. Bian, A Study of the Material Properties of Silicone Nanocomposites Developed by Electrospinning (PhD Thesis, 2013).

[92] H. F. Mark, N. Bikales, C. G. Overberger, G. Menges and J. I. Kroschwitz, Encyclopedia of polymer science and engineering, Vol. 10: Nonwoven fabrics to photopolymerization," (U.S. Department of Energy Office of Scientific and Technical Information, 1987), https://www.osti.gov/ biblio/5022853.

[93] Z. Wang, Z. D. Jia, M. H. Fang and Z. C. Guan // IEEE Transactions on Dielectrics and Electrical Insulation 22 (2015)3357. 
[94] M. Ali and R. Hackam // IEEE Transactions on Dielectrics and Electrical Insulation 16 (2009) 842.

[95] G. Yanfeng, W. Jiafu, L. Xidong, Y. Zhipeng, L. Yingyan and C. Yuanji // IEEE Transactions on Dielectrics and Electrical Insulation 21 (2014) 2428.

[96] E. A. Cherney // IEEE Transactions on Dielectrics and Electrical Insulation 12 (2005) 1108.

[97] G. Momen and M. Farzaneh // Rev.Adv.Mater.Sci 27 (2011)1.

[98] F. Ko, Y. Gogotsi, A. Ali, N. Naguib, H. Ye and G. Yang // Advanced materials 15 (2003)1161.

[99] M. Rong, M. Zhang and W. Ruan // Materials science and technology 22 (2006)787.

[100] A. Pacek, P. Ding and A. Utomo // Powder technology 173 (2007)203.

[101] R. Dave, R. Gupta, R. Pfeffer, S. Sundaresan and M. S. Tomassone, In: NSF Nanoscale Science and Engineering Grantees Conference (2006), p. 1.

[102] P. Chow and L. Gan // Journal of nanoscience and nanotechnology 4 (2004)197.

[103] S. Kim, E. Cherney and R. Hackam // IEEE Transactions on electrical insulation 27 (1992) 1065.

[104] I. Ramirez, S. Jayaram, E. A. Cherney, M. Gauthier and L. Simon // IEEE Transactions on Dielectrics and Electrical insulation 16 (2009)52.

[105] D. Tee, M. Mariatti, A. Azizan, C. See and K. Chong // Composites Science and Technology 67 (2007)2584.

[106] R. F. Gibson, Principles of composite material mechanics (CRC press, 2016).

[107] M. Ashby, S. Bush, N. Swindells, R. Bullough, G. Ellison and Y. Lindblom // Philosophical Transactions of the Royal Society of London A: Mathematical, Physical and Engineering Sciences 322 (1987)393.

[108] G. Droval, I. Aranberri, J. Ballestero, M. Verelst and J. Dexpert Ghys // Fire and Materials 35 (2011) 491.

[109] S. Raetzke and J. Kindersberger // IEEE Transactions on Dielectrics and Electrical Insulation 17 (2010)607.

[110] L. H. Sperling, Polymeric multicomponent materials: an introduction (WileyInterscience, 1997).
[111] T. Clyne and P. Withers, An introduction to metal matrix composites (Cambridge University Press, 1995).

[112] R. Gibson, Principles of composite material mechanics (New York: McGraw-Hall Inc., 1994).

[113] J. R. Weidner, F. Pohlmann, P. Gröppel and T. Hildinger, In: Proc. XVII. ISH (2011), p. 22.

[114] D. R. Cornish, Characterising electrical trees in nanocomposite epoxy-resin using partial discharge detection methods (University of the Witwatersrand, Johannesburg 2014.)

[115] W. F. Smith and J. Hashemi, Foundations of materials science and engineering (McGraw-Hill, 2011).

[116] J. F. Shackelford and M. K. Muralidhara, Introduction to materials science for engineers (Prentice Hall, 2005).

[117] V. Koutsos, In: ICE manual of Construction Materials: Volume II: Fundamentals and theory; Concrete; Asphalts in road construction; Masonry (Thomas Telford Ltd, 2009), p. 571.

[118] E. A. Campo, Selection of polymeric materials: how to select design properties from different standards (William Andrew, 2008).

[119] R. F. Landel and L. E. Nielsen, Mechanical properties of polymers and composites (CRC Press, 1993).

[120] J. E. Mark, Physical properties of polymers handbook (Springer, 2007).

[121] W. Dickstein, R. Siemens and E. Hadziioannou // Thermochimica Acta 166 (1990) 137.

[122] L. H. Meyer, E. A. Cherney and S. H. Jayaram // IEEE Electrical Insulation Magazine 20 (2004)13.

[123] A. Camenzind, T. Schweizer, M. Sztucki and S. E. Pratsinis // Polymer 51 (2010)1796.

[124] S. Kemaloglu, G. Ozkoc and A. Aytac // Thermochimica Acta 499 (2010)40.

[125] I. Ramirez, E. A. Cherney and S. Jarayam // IEEE Transactions on Dielectrics and Electrical Insulation 19 (2012)218.

[126] S. Ansorge, F. Schmuck, S. Aitken and K. Papailiou, Improved performance of silicone rubbers for the use in composite insulators (CIGRE Paper D1-105, 2010). 
[127] N. Burditt,In: , A special reciew (IEEE, 1991).

[128] B. Venkatesulu and M. J. Thomas // IEEE Transactions on Dielectrics and Electrical Insulation 17 (2010)615.

[129] P. Irwin, Y. Cao, A. Bansal and L. Schadler, In: Annual Report. Conference on Electrical Insulation and Dielectric Phenomena 2003 (IEEE, 2003), p. 120.

[130] F. Yang, Y. Ou and Z. Yu //Journal of Applied Polymer Science 69 (1998)355.

[131] E. A. Cherney // Electrical Insulation Magazine, IEEE 29 (2013)59.

[132] W. Zhou, C. Wang, T. Ai, K. Wu, F. Zhao and H. Gu // Composites Part A: Applied Science and Manufacturing 40 (2009)830.

[133] J.-W. Zha, Z.-M. Dang, W.-K. Li, Y.-H. Zhu and G. Chen // IEEE Transactions on Dielectrics and Electrical Insulation 21 (2014)1989.

[134] K. G. Budinski and M. K. Budinsk, Engineering materials: properties and selection (Prentice Hall, 1999).

[135] G. W. Ehrenstein, Polymeric materials: structure, properties, applications (Carl Hanser Verlag GmbH Co KG, 2012).

[136] C. G'sell, J. Hiver and A. Dahoun // International Journal of solids and structures 39 (2002)3857.

[137] J. J. Chruściel, In: Nanocomposite Materials: Synthesis, Properties and Applications (CRC Press, 2016), p. 173.

[138] K. Pielichowski and J. Njuguna, Thermal degradation of polymeric materials (Smithers Rapra Publishing, 2005).

[139] T. H. Thomas and T. Kendrick // Journal of Polymer Science Part A 2: Polymer Physics 7 (1969)537.

[140] K. Pielichowski, K. Flejtuch and J. Pielichowski // Polymer 45 (2004)1235.

[141] B. X. Du and H. Xu // IEEE Transactions on Dielectrics and Electrical Insulation 21 (2014)511.

[142] L. H. Meyer, S. H. Jayaram and E. A. Cherney // IEEE Transactions on Dielectrics and Electrical Insulation 12 (2005)1201.

[143] L. E. Schmidt, X. Kornmann, A. Krivda and H. Hillborg // IEEE Transactions on Dielectrics and Electrical Insulation 17 (2010)533.

[144] B. Du and H. Xu // IEEE Transactions on Dielectrics and Electrical Insulation 21 (2014) 511.
[145] R. Kumar and N. Gupta, In: IEEE Conference on Electrical Insulation and Dielectric Phenomena (CEIDP) 2015, (IEEE, 2015), p. 495.

[146] L. C. Sim, S. Ramanan, H. Ismail, K. Seetharamu and T. Goh //Thermochimica acta 430 (2005) 155.

[147] D. Chen, J. Nie, S. Yi, W. Wu, Y. Zhong, J. Liao, et al.// Polymer Degradation and Stability 95 (2010) 618.

[148] C. Chen, Z. Jia, X. Wang, H. Lu, Z. Guan and C. Yang //IEEE Transactions on Dielectrics and Electrical Insulation 22 (2015)313.

[149] Y. Li, C. Chen and Z. Jia, In: IEEE Conference on Electrical Insulation and Dielectric Phenomena (CEIDP) 2015 (IEEE, 2015), p. 721.

[150] K. Zhang, F. Wang, G. Wang and Z. Li // Journal of Applied Polymer Science 91 (2004) 2649.

[151] W. Wang, H. Chen, Y. Wu, T. Tsai and Y. Chen-Yang // Polymer 49 (2008)4826.

[152] E. Kaya, M. Tanoglu and S. Okur //Journal of applied polymer science 109 (2008)834.

[153] L. Lei, W. Xishan and C. Dengke, In: ICSD Proceedings of the 2004 IEEE International Conference on Solid Dielectrics (IEEE, 2004), p. 804.

[154] M. Y. Zhang, S. J. Zeng, T. Q. Dong, Y. Fan and Q. Q. Lei, In: 2007 IEEE International Conference on Solid Dielectrics (IEEE, 2007), p. 357.

[155] H. Zhou, Y. Fan and Q. Lei, In: 2006 IEEE 8th International Conference on Properties \& applications of Dielectric Materials (IEEE, 2006), p. 736.

[156] A. El-Hag, L. Simon, S. Jayaram and E. Cherney // IEEE Transactions on Dielectrics and Electrical Insulation 13 (2006)122.

[157] R. E. James and Q. Su // IET 53 (2008).

[158] R. Arora and W. Mosch, High voltage and electrical insulation engineering vol. 69 (John Wiley \& Sons, 2011).

[159] M. Roy, J. Nelson, R. MacCrone, L. Schadler, C. Reed and R. Keefe //IEEE Transactions on Dielectrics and Electrical Insulation 12 (2005) 629.

[160] M. Kozako, S.-I. Kuge, T. Imai, T. Ozaki, T. Shimizu and T. Tanaka // in 2005 Annual Report Conference on Electrical Insulation and Dielectric Phenomena ( IEEE, 2005), p. 162. 
[161] A. Masood, M. Zuberi and E. Husain // IEEE Transactions on Dielectrics and Electrical Insulation 15 (2008)1051.

[162] M. T. Nazir and B. Phung, In: 2015 IEEE Electrical Insulation Conference (EIC) (IEEE, 2015) 488.

[163] L. Lan, G. Yao, H. Wang, X. Wen and Z. Liu, In: 2013 Annual Report Conference on Electrical Insulation and Dielectric Phenomena (IEEE, 2013) 804.

[164] S. Alapati and M. J. Thomas // IET Science, Measurement \& Technology 6 (2012) 21.

[165] X. Huang, Y. Li, F. Liu, P. Jiang, T. lizuka and $\mathrm{K}$. Tatsumi // IEEE Transactions on Dielectrics and Electrical Insulation 21 (2014)1516.

[166] P. Barber, S. Balasubramanian, Y. Anguchamy, S. Gong, A. Wibowo and H. Gao // Materials 2 (2009) 1697.

[167] P. Kim, N. M. Doss, J. P. Tillotson, P. J. Hotchkiss, M.-J. Pan and S. R. Marder // ACS nano 3 (2009)2581.

[168] Y. Shen, E. Cherney and S. H. Jayaram, In: Conference Record of the IEEE International Symposium on Electrical Insulation 2004 (IEEE, 2004) 320.

[169] R. A. Ghunem // IEEE Electrical Insulation Magazine 31 (2015)16.

[170] M. Albright and W. Starr //Transactions of the American Institute of Electrical Engineers. Part III: Power Apparatus and Systems 3 (1956) 441.

[171] G. Sommerman // Power Apparatus and Systems 79(1960) 969.

[172] K. Mathes and E. McGowan // Transactions of the American Institute of Electrical Engineers, Part I: Communication and Electronics 80 (1961)281.

[173] Standard Test Methods for Liquidcontaminant, Inclined -Plane Tracking and Erosion of Insulating materials, ASTM D2303 (ASTM international, 1997).

[174] M. Dutta and C. K. Dwivedi, In: 3rd International Conference on Emerging Trends in Engineering and Technology (ICETET) 2010 (2010), p. 235.

[175] I. Ramirez, S. Jarayam and E. A. Cherney // IEEE Transactions on Dielectrics and Electrical Insulation 17 (2010)206.

[176] Z. Qiu, J. Ruan, D. Huang, X. Li, F. Wang and W. Yao // IEEE Transactions on Dielectrics and Electrical Insulation 22 (2015)3385.
[177] A. Krivda, L. E. Schmidt, X. Kornmann, H. Ghorbani, A. Ghorbandaeipour and M. Eriksson // IEEE Electrical Insulation Magazine 25 (2009)14.

[178] J. Holtzhausen, P. Pieterse, H. Vermeulen and S. Limbo, In: International Conference on High Voltage Engineering and Application (ICHVE) 2010 (2010), p. 445.

[179] R. A. Ghunem, S. H. Jayaram and E. A. Cherney // IEEE Transactions on Dielectrics and Electrical Insulation 21 (2014) 713.

[180] R. Sarathi, S. Chandrasekar and $\mathrm{N}$. Yoshimura //IEEE transactions on power delivery 21 (2006) 515.

[181] G. Bruce, S. Rowland and A. Krivda // IEEE Transactions on Dielectrics and Electrical Insulation 17 (2010) 521.

[182] Y. Zhou, Y. Zhang, L. Zhang, D. Guo, $X$. Zhang and $\mathrm{M}$. Wang // IEEE Transactions on Dielectrics and Electrical Insulation 23 (2016)748.

[183] A. N. Jahromi, E. A. Cherney and S. H. Jayaram // IEEE Transactions on Dielectrics and Electrical Insulation 15 (2008)444.

[184] S. Kumagai and N. Yoshimura //IEEE transactions on dielectrics and electrical insulation 6 (1999) 211.

[185] S. Chandrasekar, R. Sarathi and M. Danikas // Electrical Engineering 89 (2007)489.

[186] S. Gubanski // IEEE Electrical Insulation Magazine 21 (2005)5.

[187] L. Xidong, W. Shaowu, F. Ju and G. Zhicheng // IEEE Transactions on Dielectrics and Electrical Insulation 6 (1999)586.

[188] E. A. Cherney // IEEE Electrical Insulation Magazine 3 (2013) 18.

[189] H. Janssen, J. Seifert and H. Karner // IEEE transactions on dielectrics and electrical insulation 6 (1999) 651.

[190] J. Seifert, Internal Interfacial and Microscopic Bonding Problems in Mineral Filled Epoxies (PhD thesis, Technical University of Braunschweig, Germany, 1998).

[191] T. Tokoro, M. Nagao and M. Kosak, In: Proceedings of 1998 International Symposium on Electrical Insulating Materials (IEEE, 1998), p.461. 
[192] Y. Gao, J. Wang, X. Liang, Z. Yan, Y. Liu and Y. Cai // IEEE Transactions on Dielectrics and Electrical Insulation 21 (2014) 2428.

[193] Z. Wang, Z. Jia, M. Fang and Z. Guan // IEEE Transactions on Dielectrics and Electrical Insulation 22 (2015)3357.

[194] R. Allen // Polymer Engineering \& Science 19 (1979)329.

[195] T. Hashiguchi, N. Arise, M. Otsubo, C. Honda and O. Takenouchi, In: Annual Report Conference on Electrical Insulation and Dielectric Phenomena 1 (2000) 195.

[196] M. Ali and R. Hackam // IEEE Transactions on Dielectrics and Electrical Insulation 15 (2008) 1368.

[197] S. Manjang, I. Kitta, K. B. Muhammadia and R. N. I. Mulya, In: International Conference on Electrical Engineering and Informatics (IEEE, 2015), p.192.

[198] J. Dai, X. Yao, H. Yeh and X. Liang // Journal of applied polymer science 99 (2006) 2253.

[199] B. Lutz, Z. Guan, L. Wang, F. Zhang and Z. Lü, In: Conference Record of the 2012 IEEE International Symposium on Electrical Insulation (IEEE, 2012), p.478.

[200] R. G. Niemi, High voltage insulators, U.S. Patent No. 4,476, 15511984.

[201] N. H. Malik, A. Al-Arainy and M. I. Qureshi, Electrical insulation in power systems (Marcel Dekker, 1998).

[202] B. Bailey, J. Konstan and J. Webster, Encyclopedia of electrical and electronics engineering (Wiley, 2000).

[203] S. Marchi, Preparation and characterization of silicone nanocomposites by UV-induced hydrosilation for outdoor polymeric insulators (Politecnico di Torino, 2014).

[204] C. SUMEREDER and M. Muhr, In: 19th International Conference on Electricity Distribution (Vienna, 2007), p. 21.

[205] M. Farzaneh, In: 2009 IEEE Electrical Insulation Conference (IEEE, 2009), p. 542.

[206] R. A. Islam, Y. Chan and M. F. Islam // Materials Science and Engineering: B 106 (2004)132.

[207] R. Bartnikas, Electrical properties of solid insulating materials: measurement techniques 926 (ASTM International, 1987).

[208] N. P. Bansal and R. H. Doremus, Handbook of glass properties (Elsevier, 2013).
[209] K. Sidhu // Water and Energy International 64 (2007)20.

[210] M. T. Gencoglu and M. Uyar // Expert Systems with Applications 36 (2009) 10789.

[211] R. S. Gorur, E. A. Cherney and J. T. Burnham, In: Outdoor insulators, ed. by Ravi S. Gorur (Phoenix, Ariz, USA, 1999).

[212] R. A. Ghunem, S. H. Jayaram and E. Cherney // IEEE Transactions on Dielectrics and Electrical Insulation 20 (2013)229.

[213] M. K. Moghadam, M. Taheri, S. Gharazi, M. Keramati, M. Bahrami and N. Riahi // IEEE Transactions on Dielectrics and Electrical Insulation 23 (2016) 1805.

[214] A. UI-Hamid, K. Y. Soufi and I. Al-Hamoudi // Journal of Materials Engineering and Performance 17 (2008)280.

[215] H. Liu, G. Cash, D. Birtwhistle and G. George // IEEE Transactions on Dielectrics and Electrical Insulation 12 (2005)478.

[216] S. Carpenter and M. Kumosa // Journal of materials science 35 (2000)4465.

[217] J. Montesinos, R. Gorur, B. Mobasher and D. Kingsbury // IEEE transactions on dielectrics and electrical insulation 9 (2002) 236.

[218] J. Mackevich and M. Shah // IEEE Electrical Insulation Magazine 13 (1997)5.

[219] D. Han, H. Cho and S. Han, In: Proceedings of the 7th International Conference on Properties and Applications of Dielectric Materials 2003 (IEEE, 2003), p. 381k.

[220] R. Hackam, In: Proceedings of 1998 International Symposium on Electrical Insulating Materials 1998 (IEEE, 1998) p. 1.

[221] J. Davis and D. Rees // Proceedings of the Institution of Electrical Engineers 112 (1965) 1607.

[222] N. Mavrikakis, K. Siderakis and P. Mikropoulos, In: 49th International Universities Power Engineering Conference (UPE, 2014), p. 1.

[223] G. Haddad, K. Wong and P. Petersen // IEEE Transactions on Dielectrics and Electrical Insulation 23 (2016) 311.

[224] S. Gubanski and R. Hartings // IEEE Electrical Insulation Magazine 5 (1995)24.

[225] A. Gjerde //IEEE electrical insulation magazine 13 (1997)6. 
[226] G. C. Montanari and G. Mazzanti, Encyclopedia of Electrical and Electronics Engineering (Wiley, 1999).

[227] B. Allen, M. Bleszynski, M. Kumosa and E. Willis // IEEE Transactions on Dielectrics and Electrical Insulation 22 (2015)2978.

[228] G. Stone and R. Van Heeswijk // IEEE Transactions on Electrical Insulation $\mathbf{4}$ (1977) 253.

[229] G. Montanari and M. Cacciari // IEEE transactions on electrical insulation 3 (1985) 519.

[230] R. Sundararajan, C. Pelletier, R. Chapman, T. Pollock, R. Nowlin and T. Baker, In: 2000 Annual Report Conference on Electrical Insulation and Dielectric Phenomena (IEEE, 2000), p. 369.

[231] T. Sorqvist and A. E. Vlastos /// EEE transactions on Power Delivery 12 (1997) 1657.

[232] S. Kim, E. Cherney and R. Hackam // IEEE Transactions on Power Delivery $5(1990) 1491$.

[233] H. Kloes and D. Koenig, In" Conference Record of the 1996 IEEE International Symposium on Electrical Insulation (IEEE, 1996), p. 296.

[234] R. Niemi and T. Orbeck // IEEE Transactions on Electrical Insulation 3 (1974)102.

[235] R. S. Gorur, J. W. Chang and O. G. Amburgey // IEEE Transactions on Power delivery 5 (1990) 1923.

[236] R. Sundararajan, J. Graves, A. Mohammed and A. Baker, In: Power Engineering Society General Meeting (IEEE, 2003), p. 219.

[237] A. S. Krzma, M. Albano and A. Haddad, In: 2015 50th International Universities Power Engineering Conference (UPEC, 2015), p. 1.
[238] S.-H. Kim, E. A. Cherney, R. Hackam and K. G. Rutherford // IEEE Transactions on Dielectrics and Electrical Insulation 1 (1994)106.

[239] Y. Koshino, I. Umeda and M. Ishiwari, In: Annual Report. Conference on Electrical Insulation and Dielectric Phenomena 1998 (IEEE, 1998), p. 72.

[240] M. Ning, Q. Liu, X. Yu, Y. Chen and J. Wang, In: 2015 5th International Conference on Electric Utility Deregulation and Restructuring and Power Technologies (DRPT, 2015), p. 1472.

[241] B. Du, Z. Li and Z. Yang // IEEE Transactions on Dielectrics and Electrical Insulation 23 (2016) 3108.

[242] L. Cheng, H. Mei, L. Wang, Z. Guan and F. Zhang // IEEE Transactions on Dielectrics and Electrical Insulation 23 (2016)2850.

[243] G. C. Montanari and L. Simoni // IEEE Transactions on Electrical Insulation $\mathbf{2 8}$ (1993)755.

[244] A. Bruning and F. Campbell // IEEE transactions on electrical insulation 28 (1993)729.

[245] D. Kind and H. Kärner, High-voltage insulation technology vol. 621 (Springer 1985).

[246] J. P. Crine, In: Encyclopedia of Electrical and Electronics Engineering (Wiley, 2001), https://doi.org/10.1002/047134608X.W2816.

[247] V. K. Agarwal // IEEE transactions on electrical insulation 24 (1989)741.

[248] C. Dang, J.-L. Parpal and J.-P. Crine // IEEE transactions on dielectrics and electrical insulation 3 (1996) 237. 